\title{
Inter-hemispheric asymmetry in the sea-ice response to volcanic forcing simulated by MPI-ESM (COSMOS-Mill)
}

\author{
D. Zanchettin ${ }^{1}$, O. Bothe ${ }^{2}$, C. Timmreck ${ }^{1}$, J. Bader ${ }^{1,4}$, A. Beitsch ${ }^{1}$, H.-F. Graf ${ }^{3}$, D. Notz ${ }^{1}$, and J. H. Jungclaus ${ }^{1}$ \\ ${ }^{1}$ Max Planck Institute for Meteorology, Bundesstr. 53, 20146 Hamburg, Germany \\ ${ }^{2}$ Leibniz Institute of Atmospheric Physics at the University of Rostock, Kühlungsborn, Germany \\ ${ }^{3}$ University of Cambridge, Centre for Atmospheric Science, Downing Place, Cambridge CB2 3EN, UK \\ ${ }^{4}$ Uni Climate, Uni Reasearch and the Bjerknes Centre for Climate Research, Bergen, Norway \\ Correspondence to: D. Zanchettin (davide.zanchettin@mpimet.mpg.de)
}

Received: 7 January 2014 - Published in Earth Syst. Dynam. Discuss.: 3 February 2014

Revised: 1 May 2014 - Accepted: 14 May 2014 - Published: 25 June 2014

\begin{abstract}
The decadal evolution of Arctic and Antarctic sea ice following strong volcanic eruptions is investigated in four climate simulation ensembles performed with the COSMOS-Mill version of the Max Planck Institute Earth System Model. The ensembles differ in the magnitude of the imposed volcanic perturbations, with sizes representative of historical tropical eruptions (1991 Pinatubo and 1815 Tambora) and of tropical and extra-tropical "supervolcano" eruptions. A post-eruption Arctic sea-ice expansion is robustly detected in all ensembles, while Antarctic sea ice responds only to supervolcano eruptions, undergoing an initial short-lived expansion and a subsequent prolonged contraction phase. Strong volcanic forcing therefore emerges as a potential source of inter-hemispheric interannual-to-decadal climate variability, although the inter-hemispheric signature is weak in the case of eruptions comparable to historical eruptions. The post-eruption inter-hemispheric decadal asymmetry in sea ice is interpreted as a consequence mainly of the different exposure of Arctic and Antarctic regional climates to induced meridional heat transport changes and of dominating local feedbacks that set in within the Antarctic region. Supervolcano experiments help to clarify differences in simulated hemispheric internal dynamics related to imposed negative net radiative imbalances, including the relative importance of the thermal and dynamical components of the sea-ice response. Supervolcano experiments could therefore serve the assessment of climate models' behavior under strong external forcing conditions and, consequently, favor advancements in our understanding of simulated sea-ice dynamics.
\end{abstract}

\section{Introduction}

Polar regional climates are in the focus of earth system investigations owing to their strong sensitivity to external forcing and associated implications for the global climate. The so-called "polar amplification" of climate signals is mainly a consequence of positive feedbacks involving snow cover and sea ice, and it emerges more robustly in the Northern than in the Southern Hemisphere (e.g., Parkinson, 2004). The different behavior of Arctic and Antarctic sea ice is largely explained by the different geographical characteristics of the two polar regions: the semi-enclosed Arctic Ocean limits sea-ice mobility and favors sea-ice thickening and persistence while making Arctic sea ice strongly susceptible to changes in the Atlantic Ocean's northward heat transport and to anomalous atmospheric heat inflows from the surrounding landmasses. Antarctic sea ice, by contrast, forms around the Antarctica landmass in the open Southern Ocean, its northern boundary being set by the circumpolar system of southern midlatitude westerly winds and ocean currents. This system makes Antarctic sea ice strongly subject to equatorward drifting and melting - which explains its weak persistence while limiting its exposure to global changes and associated anomalous atmospheric and oceanic meridional heat flows (e.g., Zhang, 2007, 2014). Still, important processes driving this critical component of the earth system remain unresolved and, hence, not robustly simulated by coupled global circulation models and earth system models (e.g., Maksym et al., 2012; Turner et al., 2013; Knight, 2014). Aiming at a better understanding of simulated global sea-ice behavior and 
of its sensitivity to external forcing, this study investigates the decadal evolution of Arctic and Antarctic sea ice in a set of idealized, volcanically forced experiments conducted with a full-complexity earth system model. Focus is on interhemispheric differences in the sea-ice response.

Observations covering the past three decades point to an inter-hemispheric asymmetry in recent sea-ice cover evolution: while the decline in Arctic total sea-ice cover is among the most notable features related to present climate change (e.g., Notz and Marotzke, 2012; Stroeve et al., 2012; Wang and Overland, 2012), the Antarctic total sea-ice cover has remained steady or even increased slightly (Stammerjohn et al., 2012; Massonnet et al., 2013). The Antarctic sea-ice increase has been largest in fall, with a dipole of a regionally significant positive trend in the Ross Sea and a negative trend in the Amundsen-Bellingshausen Sea (Turner et al., 2009). Despite generally improved representations of observed seaice climatology and evolution (Stroeve et al., 2012), stateof-the-art coupled climate models fail to reproduce the observed increase in Antarctic total sea-ice cover over the last 30 years, indicating that the underlying processes are not yet simulated correctly (Turner et al., 2013). Therefore, understanding the behavior of Antarctic sea ice and improving its representation in climate models has high priority if one aims to correctly reproduce the observed Arctic/Antarctic sea-ice dichotomy (King, 2014).

Internal climate variability in historical climate simulations contributes substantially to both Arctic and Antarctic sea-ice variability (Stroeve et al., 2012; Polvani and Smith, 2013). As a consequence, simulated trends in Arctic sea ice over the last $\sim 30$ years are generally smaller than suggested by satellite-derived sea-ice products (Stroeve et al., 2012), while simulated trends in Antarctic sea ice are characterized by large inter-model differences (Polvani and Smith, 2013). Therefore, no conclusive assessment is available about whether the observed sea-ice asymmetry reflects a characteristic (either internally generated or externally forced) inter-hemispheric mode of polar climate variability or, alternatively, an extraordinary externally forced feature.

Pointing to the first hypothesis, a multicentennial control climate simulation features interdecadal periods characterized by positive trends in Antarctic sea-ice cover comparable to that observed during the last $\sim 30$ years (Turner et al., 2009). The 20th-century experienced several decades of inter-hemispheric contrast in the temperature trend (e.g., Brohan et al., 2006; Duncan et al., 2010; Chylek et al., 2010). Inter-hemispheric out-of-phase multidecadal temperature fluctuations also emerge from reconstructed regional- and continental-scale temperature variability during the last millennium and beyond (Holden et al., 2010; Ahmed et al., 2013). Paleoclimatic records for the last glacial maximum similarly indicate that heterogeneity and nonsynchronous behavior of polar ice sheets and glacier behavior is a characteristic feature of millennial-scale cli- mate variability (Schaefer et al., 2009; Weber et al., 2011; Shakun et al., 2012). The core processes implicated in these low-frequency inter-hemispheric climate fluctuations may be similarly important for sub-centennial Arctic/Antarctic climate variability.

The hypothesis of an externally forced inter-hemispheric asynchronism implies the existence of regional forcing agents and/or of response mechanisms to global forcing agents that are capable of driving a (multi)decadal interhemispheric climate offset. Stratospheric ozone depletion in the Southern Hemisphere is among the regional factors capable of affecting Antarctic sea ice, especially through tendential changes induced in the large-scale tropospheric circulation of the Southern Hemisphere (Gillett and Thompson, 2003; Turner et al., 2009). Coupled climate simulations including time-varying stratospheric ozone, however, do not support a causal relationship between stratospheric ozone depletion and increased Antarctic sea ice (Sigmond and Fyfe, 2014).

Strong volcanic eruptions are a likely candidate for a natural forcing agent that acts globally and yet causes pronounced differences in the inter-hemispheric response: for the Arctic, climate simulations indicate explosive volcanism as a major source of near-decadal (Stenchikov et al., 2009; Segschneider et al., 2013; Zanchettin et al., 2012, 2013a) and multidecadal-to-centennial (Zhong et al., 2011) fluctuations in the total sea-ice area. A volcanically forced Arctic seaice expansion has been suggested as being pivotal in the onset and sustenance of the Little Ice Age (Miller et al., 2012; Schleussner and Feulner, 2013), the prolonged widespread cold period spanning the 15 th-18th centuries. The same period, however, features a pronounced reduction of latesummer Arctic total sea-ice extent in a recent millennial reconstruction (Kinnard et al., 2011), counterintuitive behavior that highlights the complexity of the dynamical processes behind low-frequency variability of sea ice and our still limited knowledge about the climate state and the mechanism(s) behind specific anomalous episodes (e.g., Zanchettin et al., 2013a).

Scientific literature lacks studies about the susceptibility of Antarctic sea ice to volcanic forcing. There are no sufficiently resolved reconstructions of Antarctic sea ice to assess anomalies during periods of strong volcanism before the satellite era, or they lack context as, for instance, the sofar isolated estimate of Antarctic sea-ice extent of September 1964 (Meier et al., 2013) during the aftermath of the 1963 eruption of Mount Agung. Diagnosed dynamical atmospheric responses to the strongest 20th-century eruptions are not robust in the Southern Hemisphere in observations and especially in simulations (e.g., Robock et al., 2007; Karpechko et al., 2010; Charlton-Perez et al., 2013). Generalizing assessment based on the 20th-century eruptions is prevented by the paucity and limited magnitude of the considered events and by their concomitance with known potential disturbances to the post-eruption Antarctic climate 
evolution. Such disturbances include internal (e.g., a large warm event of the El Niño-Southern Oscillation or ENSO) and external ones. The latter would include, e.g., a period of weak solar activity (Barlyaeva et al., 2009) and the ozone hole (Bitz and Polvani, 2012). In fact, Antarctic sea ice expands considerably in the aftermath of a "supervolcano" eruption simulated by a coupled climate model (Jones et al., 2005). Confronting the supervolcano response with the lack of a clear response to 20th-century eruptions poses the question of whether a possible southern-hemispheric dynamical response remains elusive due to a low signal-to-noise ratio for historical eruptions.

In this study, we assess the simulated inter-hemispheric sea-ice response to idealized volcanic perturbations by pursuing the following strategy: (i) investigating ensembles of earth system model simulations that are sufficiently populated to yield a robust estimate of the expected forced response; (ii) comparing ensemble-average simulated responses induced by volcanic perturbations of different magnitude, ranging from that of a 1991 Pinatubo-size eruption to those of supervolcano-size eruptions. By including the latter we explore responses to forcing amplitudes pushing the simulated climate to its extremes. In the past, comprehensive assessments of climate responses under idealized external forcings as those used here have been proven valuable to understanding simulated climate features and mechanisms and, consequently, to delimiting the validity of model-based inferences about climate dynamics and variability, as well as to compare the performance of different climate models (e.g., Stouffer et al., 2006). Accordingly, we focus on the inter-hemispheric asymmetry in simulated sea-ice behavior, but we also discuss possible limitations in the realism of the simulated sea-ice behavior in light of the ocean-atmospheresea-ice-coupled dynamics inferred from the analysis of the simulation ensemble. Our assessment therefore delineates how deficiencies in, e.g., the representation of the Southern Ocean (e.g., Russell et al., 2006; Weijer et al., 2012; Heuzé et al., 2013; Salleé et al., 2013), of the Southern Hemisphere's atmospheric circulation (Simpson et al., 2012; Stössel et al., 2011) and of sea-ice processes relevant for the Antarctic (Landrum et al., 2012; Maksym et al., 2012) may have an effect on simulated transient global climate variability.

We proceed as follows. First, in Sect. 2 we detail the experimental design of this study, including the earth system model, the simulations and the diagnostic tools. In Sect. 3 we present the characteristics of the simulated climate responses to the imposed forcing, focusing on post-eruption fluctuations in Arctic and Antarctic sea ice and highlighting interhemispheric differences in the (forced) post-eruption signals and associated dynamics. We discuss our results in Sect. 4 and provide conclusive remarks in Sect. 5.

\section{Data and methods}

We use the Max Planck Institute Earth System Model (MPIESM) in its COSMOS-Mill version. The name of this version reflects the fact that the Community Earth System Modeling (COSMOS) used it for its Millennium Experiment, as described by Jungclaus et al. (2010), who provide a detailed description of the model setup. MPI-ESM-COSMOSMill is based on the atmospheric general circulation model ECHAM5 (Roeckner et al., 2006) coupled with the ocean model MPIOM (Marsland et al., 2003; Jungclaus et al., 2006) via the OASIS3 coupler. Modules for terrestrial biosphere (JSBACH; see Raddatz et al., 2007) and for ocean biogeochemistry (HAMOCC; see Wetzel et al., 2005) allow for an interactive representation of the carbon cycle. The ECHAM5/MPIOM-coupled general circulation model participated in the Coupled Model Intercomparison Project 3 (CMIP3), and has been extensively evaluated in that context. Jungclaus et al. (2006) describe the general climatological oceanic features of ECHAM5/MPIOM, including Arctic and Antarctic sea ice: simulated sea-ice concentrations generally compare well to the observations in both hemispheres, and seasonal variation and mean distribution of Antarctic sea-ice concentrations are overall satisfactorily simulated, though the model tends to underestimate winter sea-ice concentration in the Weddell Sea and the Ross Sea. Koldunov et al. (2010) provide a detailed evaluation of Arctic seaice variability simulated by ECHAM5/MPIOM compared to late-20th-century observations. Notz and Marotzke (2012) showed that the internal variability of Arctic sea-ice cover as simulated by ECHAM5/MPIOM agrees favorably with the observed internal variability.

In MPI-ESM-COSMOS-Mill, ECHAM5 is run in its T31L19 configuration, corresponding to a spatial resolution of $3.75^{\circ} \times 3.75^{\circ}$ and 19 vertical levels with the highest one (i.e., the model top) set to $10 \mathrm{hPa}$. The model's low top restricts the description of stratospheric and coupled stratosphere-troposphere dynamics (e.g., Omrani et al., 2014), which may affect the dynamical atmospheric response to volcanic forcing (e.g., Charlton-Perez et al., 2013). MPIOM is run in its standard configuration GR30L40, corresponding to a horizontal grid spacing of about $3.0^{\circ}$ and 40 vertical levels. It embeds a dynamic-thermodynamic Hiblertype sea-ice model. A detailed description of the treatment of sub-grid-scale mixing, and of the sea-ice dynamics and thermodynamics implemented in MPIOM is provided by Marsland et al. (2003).

A number of studies have evaluated the climate and its variability as simulated by MPI-ESM-COSMOS-Mill against observations, proxy-based reconstructions and within a multi-model framework (e.g., Henriksson et al., 2012; Beitsch et al., 2013; Bothe et al., 2013; Fernández-Donado et al., 2013; Schubert et al., 2013; Zanchettin et al., 2012, 2013a, b). In particular, Beitsch et al. (2013) showed that MPI-ESM-COSMOS-Mill spontaneously generates positive 
decadal-scale temperature anomalies in the Arctic region that are compatible with the observed episode known as the "early twentieth-century warming". Tietsche et al. (2011) explored recovery mechanisms of Arctic summer sea ice through perturbation experiments conducted with ECHAM5/MPIOM in the same configuration as MPI-ESMCOSMOS-Mill. C. Li et al. (2013) used idealized global warming simulations performed with ECHAM5/MPIOM in the same configuration to explore the long-term stability of Arctic and Antarctic sea ice in relation to slow changes in atmospheric $\mathrm{CO}_{2}$ concentration. Climatological characteristics of sea-ice concentration simulated by MPI-ESM-COSMOSMill are provided in the supplement (Figs. S1 and S2 in the Supplement). They agree well with those described by Jungclaus et al. (2006) for ECHAM5/MPIOM.

Four simulation ensembles are considered describing the climatic effects of idealized volcanic perturbations of different magnitude, up to supervolcano-size eruptions. The four ensembles consist of (i) 10 simulations forced by a 1991 Pinatubo-like tropical eruption; (ii) 10 simulations forced by a 1815 Tambora-like tropical eruption; (iii) 5 simulations forced by a Young Toba Tuff (Toba)-like eruption, i.e., a tropical eruption with 100 times the emission strength of the Pinatubo eruption; and (iv) 10 simulations forced by a Yellowstone-like eruption (i.e., the same as Toba, but located in the Northern Hemisphere's midlatitudes). In the following, we refer to the ensembles avoiding the volcanoes' specific names to highlight their idealized character. We thereafter refer to the Pinatubo and Tambora simulations/eruptions as "historical" (namely HIST1 and HIST2, respectively), since these eruptions are representative of the magnitude of volcanic eruptions that occurred during the last millennium. The Toba and Yellowstone supervolcano ensembles are referred to as SUPER1 and SUPER2, respectively. HIST2 corresponds to the VO2 ensemble in Zanchettin et al. (2013a). SUPER1 entails the simulations used in Timmreck et al. (2010, 2012). SUPER2 simulations are those described in Segschneider et al. (2013). Each ensemble consists of simulations differing only in their initial climate states, which are sampled from a multi-millennial preindustrial control simulation (as used in Timmreck et al., 2010, and Zanchettin et al., 2013a). In HIST1, SUPER1 and SUPER2 the eruptions start in June of the first integration year. In HIST2 the eruption starts in April, according to historical reconstructions of the 1815 Tambora event (Crowley et al., 2008; Crowley and Untermann, 2013). HIST2 simulations include the eruptions reconstructed for the subsequent decades, e.g., the Cosiguina eruption in the early 1830s (Zanchettin et al., 2013a).

Volcanic forcing implemented in MPI-ESM is based on zonally averaged time series of aerosol optical depth (AOD) at $0.55 \mu \mathrm{m}$ and of effective particle radius $\left(R_{\text {eff }}\right)$. For HIST2, we use the reconstructed 10-day average values of AOD and $R_{\text {eff }}$ by Crowley et al. (2008). Data are provided for four equal-area latitudinal bands $\left(90-30^{\circ} \mathrm{S}, 30^{\circ} \mathrm{S}-0^{\circ}, 0-30^{\circ} \mathrm{N}\right.$ and $\left.30-90^{\circ} \mathrm{N}\right)$. Volcanic aerosols are vertically distributed between 30 and $70 \mathrm{hPa}$, with a maximum at $50 \mathrm{hPa}$ (Timmreck et al., 2009). For the other ensembles, AOD and $R_{\text {eff }}$ are estimated following the two-step approach described by Timmreck et al. (2010). To briefly summarize: in the first step the formation of volcanic sulfate aerosols is calculated from an initial volcanic sulfur injection into the stratosphere by the middle atmosphere version of the aerosol climate model ECHAM/HAM (Stier et al., 2005; Niemeier et al., 2009); in the second step, the zonally averaged monthly time series of the AOD and $R_{\text {eff }}$ values calculated in this way are used as external forcing in MPI-ESM. Due to subsequent temporal interpolation of input data by ECHAM5, in MPIESM the eruption is tailed in the month preceding its occurrence in ECHAM/HAM.

In all simulations, the time-dependent AOD and $R_{\text {eff }}$ values are used to calculate online the optical parameters of the ECHAM5 radiation scheme, including extinction, singlescattering albedo and asymmetry factor for the six solar bands $(0.185-4 \mu \mathrm{m})$, and extinction for the 16 long-wave wavelength bands $(3.3-100 \mu \mathrm{m})$. Aerosol sizes are assumed to be distributed with a constant standard deviation of $1.8 \mu \mathrm{m}$.

The global-average air surface temperature drop after the 1991 Pinatubo eruption in sensitivity experiments conducted with MPI-ESM is comparable to observations (Timmreck et al., 2009). Global and hemispheric near-surface air temperature changes in a full-forcing COSMOS-Mill simulation ensemble around the Tambora eruption employing the same volcanic forcing input as the HIST2 ensemble are compatible with estimates from observations and reconstructions (Zanchettin et al., 2013a).

Responses are diagnosed through an analysis of ensemble averages. For time series, we use deseasonalized and then low-pass filtered values. Seasonality is computed based on control-run data and then subtracted from all data. Filtering consists of a 3-month centered running mean for atmospheric variables and a 13-month centered running mean for oceanic and sea-ice variables, unless specified otherwise. Anomalies are evaluated as deviations from the pre-eruption climatology, defined as the mean climate state during the 10 years/winters/summers preceding the eruption. Post-eruption years are progressively numbered starting from the year of the eruption, which is defined as year 0 .

A Monte Carlo approach is used to estimate the statistical significance of the forced signals (e.g., Graf and Zanchettin, 2012). Specifically, the ensemble-average signals obtained from an ensemble of $n$ forced simulations are compared with a large set of analog ensemble-average signals (here 500) obtained by randomly sampling $n$ years along the whole length of the control run. The empirical distribution yielded by these analog ensemble-average signals probabilistically describes the range explicable by internal variability alone, which we also interpret as the confidence level of corresponding signals in the forced ensembles having occurred by chance. We consider the $98 \%$ range (i.e., 1st-99th percentile band) of 
such distribution as reference in order to have a conservative estimate of internal variability signals. Since the procedure is only based on the random selection of years, the autocorrelation is preserved in the estimation of the significance.

Total sea-ice area in the Arctic and in the Antarctic is calculated as the areal sum of sea ice covering the ocean in the Northern and Southern Hemispheres, respectively. Analogously, total sea-ice volume is defined as the sum of local (i.e., grid point) products of grid cell area and grid-cellaverage sea-ice thickness. The sea-ice edge is defined as the line denoting the sea-ice extent margin, i.e., the area enclosing sea-ice concentrations exceeding the 0.15 threshold (in the range [0:1], where 0 indicates no sea ice in the grid cell and 1 indicates sea ice fully covering the grid cell).

Meridional ocean heat transports (HT) are calculated at $60^{\circ} \mathrm{N}$ and $60^{\circ} \mathrm{S}$ as in Zanchettin et al. (2012), based on the equation $\mathrm{HT}=\Sigma_{z} \Sigma_{x} v T c_{\mathrm{p}} \rho \mathrm{d} x \mathrm{~d} z$, where $v$ is the meridional velocity component, $T$ is temperature, $c_{\mathrm{p}}$ is specific heat capacity at constant pressure, $\rho$ is density, and $\mathrm{d} z$ and $\mathrm{d} x$ represent, respectively, the integrals along depths and longitudes. The zonal mean component of the total meridional ocean heat transports is considered to be associated with the overturning transport; the residual component is considered to describe the gyre contribution to the total meridional ocean heat transport. Accordingly, deviations of $v$ and $T$ from the respective zonal mean values are used in the abovementioned equation for the calculation of the gyre contribution to HT.

The meridional atmospheric energy transport around $60^{\circ} \mathrm{N}$ and $60^{\circ} \mathrm{S}$ is defined, following Keith (1995), as the zonal integral at, respectively, $61.23^{\circ} \mathrm{N}$ and $61.23^{\circ} \mathrm{S}$ of the convergence of the atmospheric energy transport vector $\boldsymbol{F}_{\mathrm{A}}$, which can be written for latitude $\lambda$ as

$$
\begin{aligned}
\boldsymbol{F}_{\lambda}= & \int_{\lambda}-\nabla \cdot \boldsymbol{F}_{\mathrm{A}} \mathrm{d} x=\int_{\lambda}-\nabla \cdot \frac{1}{g} \\
& \int_{0}^{p_{\mathrm{s}}}\left(c_{\mathrm{p}} T+\Phi+L q+k\right) \boldsymbol{v} \mathrm{d} p \mathrm{~d} x,
\end{aligned}
$$

where $\mathrm{d} p$ and $\mathrm{d} x$ represent, respectively, the integral along pressure levels and longitudes, and $c_{\mathrm{p}} T+\Phi$ represents dry static energy, with the specific heat of the atmosphere at constant pressure $c_{\mathrm{p}}$, temperature $T$ and geopotential $\Phi$. Moist static energy is depicted by $c_{\mathrm{p}} T+\Phi+L q$, with latent heat of evaporation/condensation $L$ and specific humidity $q$. The horizontal wind vector is represented by $\boldsymbol{v}$. As kinetic energy $k$ is typically a small component of the energy budget, it is ignored in the following. The small latitudinal difference between atmospheric and oceanic heat transport calculations is of negligible concern, since we do not aim to close the energy budget for the two regions.

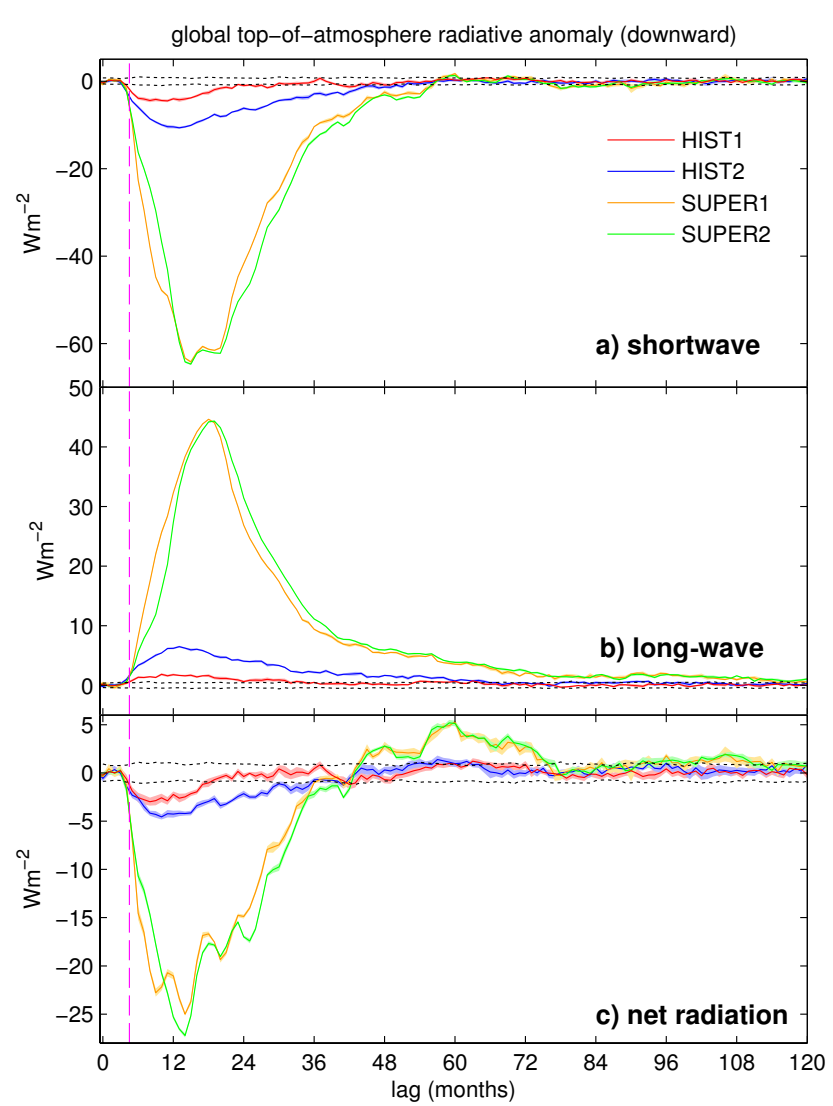

Figure 1. Simulated imposed forcing in the two historical and the two supervolcano ensembles as diagnosed through anomalies in the global-average top-of-atmosphere solar (shortwave, a), thermal (long-wave, b) and net (c) radiation. Lines and shading represent the mean and standard error of the mean respectively. Black dotted lines indicate the internal variability range $(n=10$; see methods). The dashed vertical magenta line indicates the approximate start of the eruptions. $\operatorname{Lag}(0)$ corresponds to January of the eruption year. Positive anomalies correspond to increased downward flux. No smoothing was applied to the series.

\section{Results}

\subsection{Imposed forcing and global/hemispheric responses}

The imposed forcing is very well constrained within each of the four ensembles (Fig. 1). Estimates based on topof-atmosphere radiative anomalies for individual ensembles are consistent with previously reported ones (Timmreck et al., 2010; Segschneider et al., 2013; Zanchettin et al., 2013a); we therefore only describe major features and inter-ensemble differences. Especially during the first three post-eruption years, ensemble standard errors are barely distinguishable from the corresponding ensemble-average values. Peak negative anomalies in the global top-of-atmosphere net radiative flux range between $\sim-3 \mathrm{Wm}^{-2}$ for HIST1 and $\sim-27 \mathrm{Wm}^{-2}$ for SUPER2 (Fig. 1c). SUPER2 leads to a slightly stronger forcing than SUPER1 in the net radiative 
flux estimate (Fig. 1c). This highlights the dependence of the net forcing on the shape of post-eruption evolutions of the shortwave and long-wave radiation flux anomalies, since these have otherwise similar peak values in the two ensembles (Fig. 1a, b). The evolution of radiative fluxes is directly linked to the evolution of the volcanic aerosol mass, which builds up more slowly during the first post-eruption months in SUPER2 compared to SUPER1 (not shown). This seems to be the key to understanding the differences between the two supervolcano ensembles and the distinguishing traits of SUPER2. The positive net flux anomaly around lags of 42 to 78 months is mainly a consequence of the ocean releasing less latent heat to the atmosphere (Timmreck et al., 2010; Zanchettin et al., 2013a).

On the global scale, the four ensembles depict significant post-eruption drops in surface $(2 \mathrm{~m})$ air temperature and precipitation (Fig. 2a, b). Cold temperature anomalies consistently peak in the boreal summer to fall of year 1, i.e., slightly after the peak in the forcing (compare with Fig. 1c), with a larger ensemble spread for the historical eruptions (note that SUPER1 consists of only five simulations). HIST1 displays a temporary initial recovery of the temperature signal to within the internal variability range in year 2 , when a warm ENSO event typically sets in. The ensemble-mean simulated maximum cooling for HIST1 matches the observed maximum cooling of $0.4 \mathrm{~K}$ estimated for the Pinatubo by Thompson et al. (2009). Annual oscillations in the posteruption anomalous temperature evolution in the supervolcano ensembles indicate a seasonal differentiation of the response, with boreal winter semesters being comparatively colder than summer ones from year 2 onwards. The global temperature responses differ appreciably between SUPER1 and SUPER2. Inter-ensemble differences in global precipitation relate to the timing of the post-eruption fluctuation, delayed in the case of SUPER2 compared to SUPER1, rather than the shape of the post-eruption fluctuation and its peak value. Post-eruption anomalies of hemispheric-average surface air temperature (Fig. 2c, d) further highlight the differences between historical and supervolcano eruptions. For the two historical eruptions, inter-hemispheric differences are small and remain mostly confined to the internal variability range after the first two post-eruption years (Fig. 2d). For the supervolcano ensembles, inter-hemispheric differences are large and remarkably independent of the location of the eruption (Fig. 2d): the Northern Hemisphere undergoes a much stronger and longer-lasting cooling compared to the historical ensembles (Fig. 2c), with a more pronounced seasonal character than the Southern Hemisphere (compare Fig. 2d). As a consequence, in both supervolcano ensembles the anomalous hemispheric temperature evolutions deviate considerably from the global estimate.

Overall, we diagnose qualitatively similar features in the different ensembles that point to an amplification of the forced global signals with increased magnitude of the eruption. Supervolcano simulations feature a high signal-to-noise ratio, and even the five-member SUPER1 ensemble is suitable for robust global- and hemispheric-scale inferences. Inter-hemispheric differences are apparent in the surface air temperature responses to supervolcano eruptions but not to those that are comparable to historical eruptions, suggesting that substantially different dynamical responses may characterize the different eruption sizes.

\subsection{Sea-ice response}

The post-eruption anomalies of Arctic and Antarctic sea-ice area and volume depict major inter-hemispheric differences in the sea-ice responses to both historical and supervolcano eruptions (Fig. 3). In the Arctic, the total sea ice expands for all eruptions (Fig. 3a, c). The post-eruption positive anomalies of total Arctic sea-ice area and volume are of comparable magnitude for the two historical eruptions, but their timing differs. Total Arctic sea-ice area and volume anomalies are about one order of magnitude larger in the supervolcano ensembles than in the historical ones. In both ensembles, total sea-ice area and volume entail a sharp increase in simulation years 1 and 2, which is followed by a decadal-scale progressive dampening of the anomaly. The larger anomalies in SUPER2 compared to SUPER1 are likely thermally driven: the volcanic cloud produced by the extra-tropical Yellowstonelike eruption is more confined to the Northern Hemisphere and produces a stronger radiative effect there, i.e., stronger cooling (Fig. 2d). The system fully reverts back to within the internal variability range in about 2-2.5 decades.

Significant post-eruption anomalies of Antarctic total seaice area and volume (Fig. 3b, d) are only detected in the supervolcano ensembles. In these ensembles and especially concerning the total sea-ice volume, Antarctic sea-ice anomalies are much smaller than their Arctic counterparts (compare panels (c) and (d) of Fig. 3). This is true for both the actual anomalies and their values relative to the preeruption climatology (which is shown in Fig. 3). Initially, a short-lived Antarctic sea-ice area increase occurs approximately within the first two post-eruption years, and this is not accompanied by a significant increase in sea-ice volume. This means that, in contrast to the Arctic sea-ice response, there is no post-eruption net buildup of Antarctic sea-ice mass. As we will further discuss in Sect. 3.3, the areal expansion likely results in good part from a dynamic response of the Southern Ocean's sea ice, which is advected over a larger area. This initial expansion phase is followed by a rebound retraction phase of similar amplitude and longer duration (Fig. 3b); this phase is characterized by a drastic reduction in the total sea-ice volume (Fig. 3d). Note that a reduction in sea-ice volume starts in year 1 , when the positive anomaly in sea-ice area is near its peak, meaning that net losses in volume occur already during the horizontally expanded phase of Antarctic sea ice. In other words, Antarctic sea ice covers a larger area while thinning. This second phase consistently ends about eight years after the eruption. Negative anomalies 

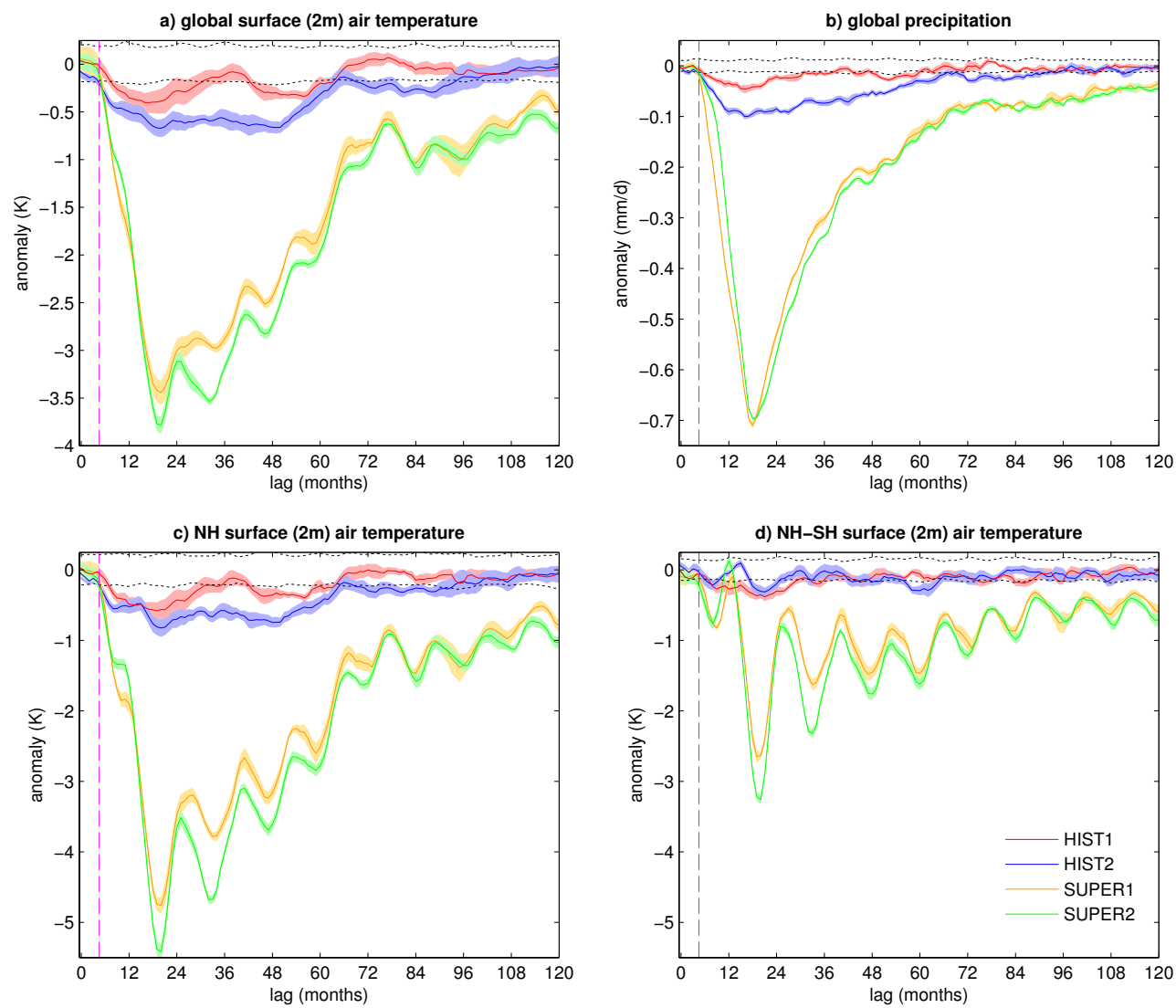

Figure 2. Simulated post-eruption anomalies of global-average surface ( $2 \mathrm{~m}$ ) air temperature (SAT) (a) and total precipitation (b), northernhemispheric average SAT (c), and the difference between northern- and southern-hemispheric average SAT (d) for the two historical and the two supervolcano ensembles. Lines and shading represent the mean and the standard error of the mean respectively. Black dashed lines indicate the internal variability range ( $n=10$; see methods). The dashed vertical magenta line indicates the approximate start of the eruptions. $\operatorname{Lag}(0)$ corresponds to January of the eruption year. Note that the $y$ axis in panels (c) and (d) has the same scale, highlighting the relative magnitude of inter-hemispheric differences in the temperature response.

of both sea-ice area and volume are larger for SUPER1, whose ensemble spread nonetheless overlaps with that of SUPER2 during the full duration of the rebound fluctuation.

Generally, ensemble spreads are larger in the Antarctic sea-ice area estimates than in their Arctic counterparts. This is true also for the spread in sea-ice volume in its relative estimates but not in its absolute values due to smaller Antarctic climatology (Fig. 3c, d). Overall, the post-eruption seaice evolution appears to be characterized by two distinct phases in the supervolcano ensembles: (i) an initial phase of tendential synchronic bipolar expansion during integration years 1 and 2, and (ii) a subsequent, prolonged phase of interhemispheric asymmetry during integration years 4-6.

The anomalies determining the two detected phases of post-eruption sea-ice evolution have a prominent seasonal character (Fig. 4). In the historical ensembles, the significant signals detected in the deseasonalized and smoothed series of total Arctic sea-ice area (Fig. 3a) originate from a significant increase during the boreal summer season (Fig. 4a). In the supervolcano ensembles the initial post-eruption increase in total Arctic sea-ice area occurs throughout the whole year but the magnitude of departures from the climatology is more than doubled in the boreal summer compared to the boreal winter. As we will show in Sect. 3.3, this behavior is most likely due to reduced melting, i.e., thermodynamics is very important for the initial response of Arctic sea ice to volcanic forcing. Predominance of reduced summer melting on winter growth is less pronounced in the Arctic delayed response, and the annual cycle averaged over years 4-6 essentially corresponds to an upward-shifted unperturbed annual cycle (Fig. 4c). By contrast, the signals in total Antarctic sea-ice area are largest in the sea-ice growth season (Fig. 4b), with initial post-eruption gains peaking at $\sim 1.9-2.4$ million $\mathrm{km}^{2}$ in June-July, and following losses peaking at $\sim 1.8-2$ million $\mathrm{km}^{2}$ in August-October (Fig. 4d).

Figures 5 and 6 illustrate the regional distribution of sea-ice concentration anomalies for, respectively, the Arctic and the Antarctic region during the two detected phases of post-eruption sea-ice evolution for the SUPER1 ensemble. Mapped values refer to monthly anomalies at the end of the 

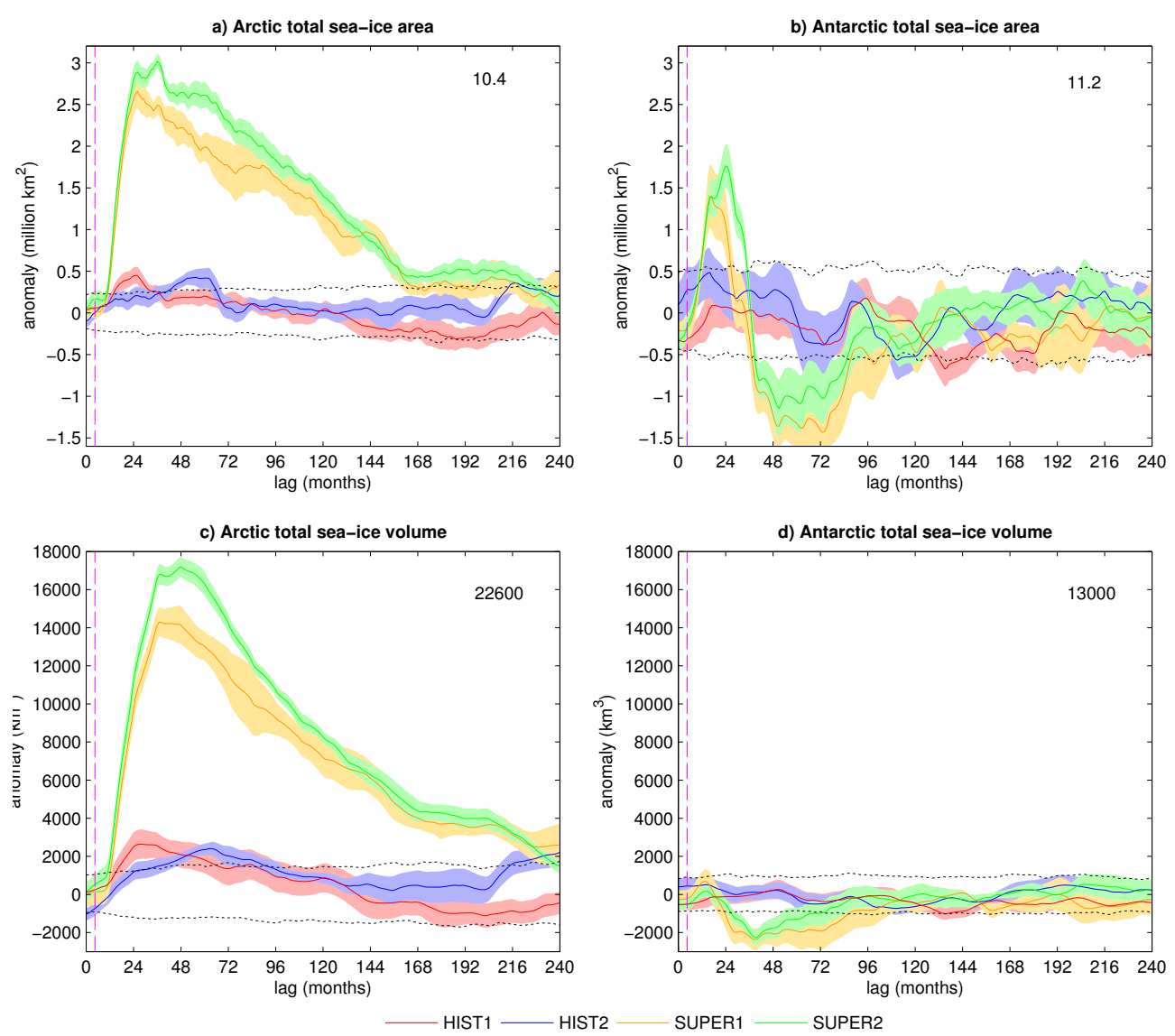

Figure 3. Simulated post-eruption anomalies of Arctic (left) and Antarctic (right) total sea-ice area (top panels) and volume (bottom) for the two historical and the two supervolcano ensembles. Lines and shading represent the mean anomaly and the standard error of the mean respectively. Anomalies are smoothed with a 13-month centered moving average. Black dashed lines indicate the internal variability range ( $n=10$; see methods). The dashed vertical magenta line indicates the approximate start of the eruptions. $\operatorname{Lag}(0)$ corresponds to January of the eruption year. The number on the top right of each panel is the approximate pre-eruption climatology. The $y$ axis has the same scale in panels (a) and (b) as in panels (c) and (d), highlighting the different magnitude of the hemispheric responses.

growing season (i.e., March for Arctic sea ice, September for Antarctic sea ice) and of the melting season (i.e., September for Arctic sea ice, March for Antarctic sea ice). Immediately after the eruption, the March Arctic sea-ice concentration increases especially in the gulf of Alaska/eastern Bering Sea and in the outer Labrador Sea/western North Atlantic, where the sea-ice edge advances significantly (Fig. 5a). Widespread reduced melting results in extensive increases in September Arctic sea-ice concentrations. These are particularly large in the Canadian Arctic Archipelago and in Baffin Bay, where the sea-ice edge advances as far as the Hudson and Davis Straits, along the East Greenland current, and into the Barents and Kara seas, with the latter basin being fully sea ice covered (Fig. 5c). The same regions are important for the total Arctic sea-ice area anomaly in the second phase of the post-eruption areal evolution of sea ice. Then, the strongest contribution to the winter anomaly of Arctic total sea-ice area comes from the North Atlantic/Nordic seas sector, where March sea-ice concentrations increase by as much as $60 \%$
(Fig. 5b). September Arctic sea-ice concentration anomalies are also still significant over extensive regions, but with smaller amplitudes overall (Fig. 5d).

In the Antarctic, total sea-ice area anomalies are of reduced amplitude and extension in austral summer during both phases (Fig. 4b, d). Immediately after the eruption, there is a circumpolar tendency towards positive March anomalies of sea-ice concentration, though these are strongest and most extensive off the West Antarctica coast, where they result in a local advance of the sea-ice edge (Fig. 6a). Later on, the same region faces a marked reduction of March sea-ice concentrations and a consequent retreat of the sea-ice edge (Fig. 6b), which is again part of a general circumpolar tendency. The regional details of September anomalies of Antarctic sea-ice concentration during the two phases provide a more complex picture (Fig. 6c, d). In both phases, negative sea-ice concentration anomalies are diagnosed off the East Antarctic coasts and in the outer Weddell Sea. In the latter region, the response has the typical traits of an open-ocean polynya, 

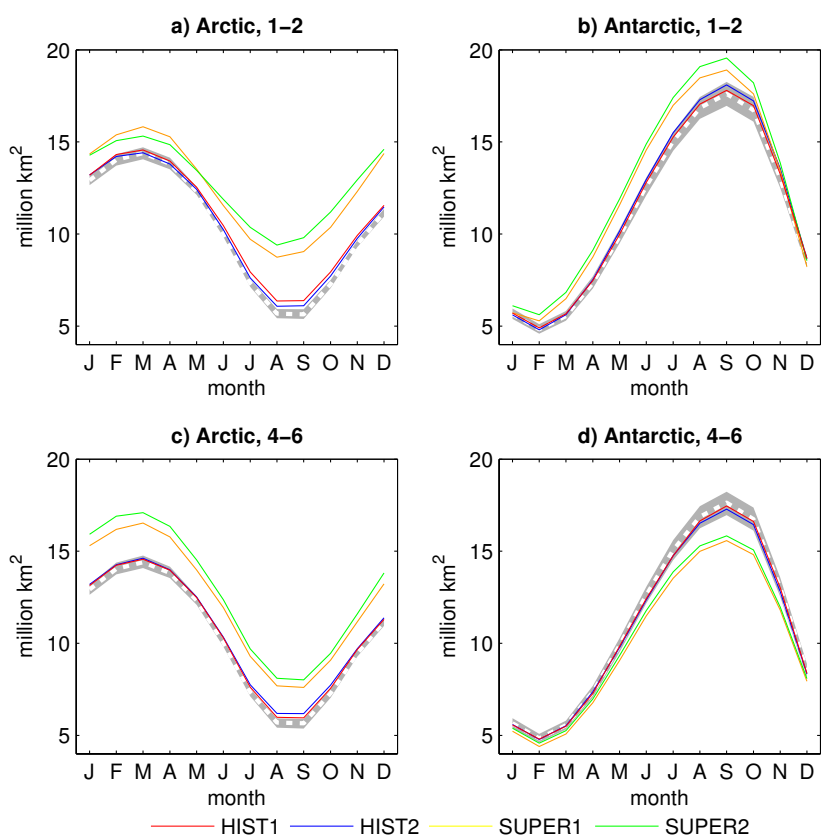

Figure 4. Ensemble-mean simulated seasonal evolutions of hemispheric sea-ice area for integration years 1-2 (a, b) and 4-6 (c, d) for the two historical and the two supervolcano ensembles. Gray shading and the dashed white line represent the $98 \%$ range and the mean, respectively, for signal occurrence in the control run. The signal in the control run corresponds to the annual evolution averaged over three randomly chosen consecutive years for a 10-member ensemble.

i.e., an ice-free area within the ice cover, and is surrounded by positive anomalies leading to a locally advancing sea-ice edge during the initial post-eruption phase (Fig. 6c). Anomalies extend more widely spatially in the second phase, when a general retreat of the sea-ice edge is diagnosed (Fig. 6d). Whereas no significant large-scale changes are detected west of the Antarctic Peninsula in the initial phase (Fig. 6c), the same region later faces a reduction in sea-ice concentration which is locally as large as $60 \%$ and results in a strong retreat of the sea-ice edge (Fig. 6d). Whereas both phases indicate reductions in September sea-ice concentrations in the outer Ross Sea, the initial post-eruption phase also entails an extensive increase along $60^{\circ} \mathrm{S}$ (Fig. 6c).

Differences between the shown SUPER1 patterns and their SUPER2 analogues (not shown) are generally minor. For historical eruptions, significant post-eruption sea-ice concentration anomalies are usually local, but generally point towards an agreement with the supervolcano ensembles concerning the tendencies in the key regions (not shown).

In summary, the sea-ice response to volcanic eruptions in MPI-ESM-COSMOS-Mill strongly depends on the amplitude of the induced global perturbation and, to a lesser extent, the location of the eruption (compare, e.g., the Arctic sea-ice response to the SUPER1/tropical and SUPER2/midlatitude eruptions). All ensembles feature a temporary post-eruption
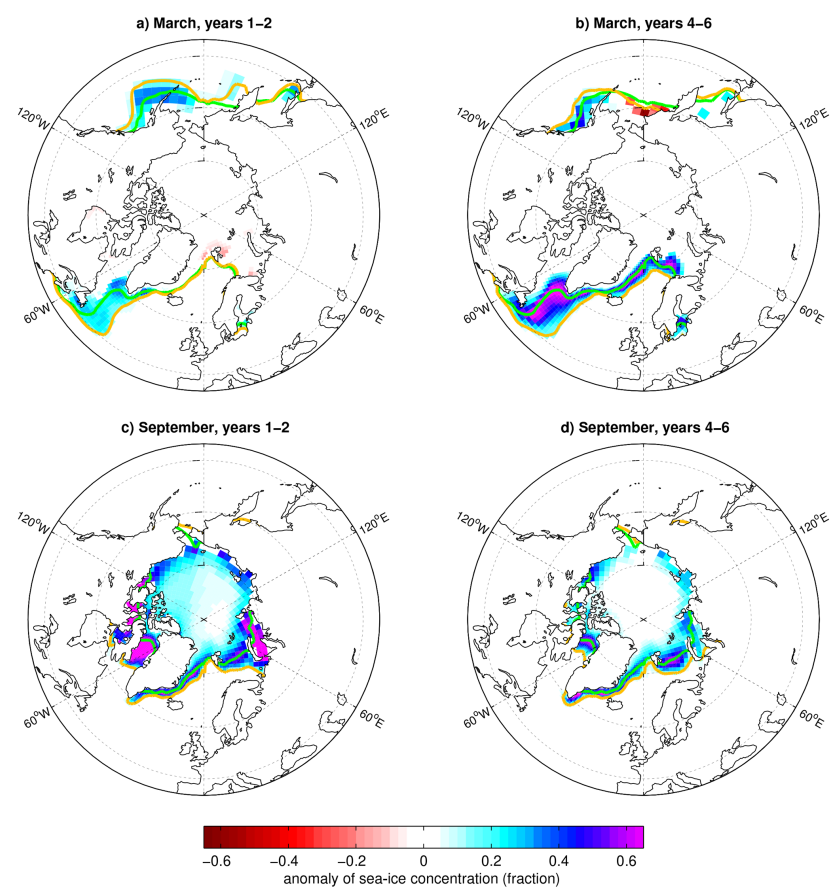

Figure 5. Ensemble-mean simulated March (top panels) and September (bottom panels) Arctic sea-ice concentration anomalies for integration years 1-2 (a, b) and 4-6 (c, d) of the SUPER1 ensemble. Only grid points where the anomaly is significant at $95 \%$ confidence ( $n=5$; see methods) are shown. The green and orange lines indicate, respectively, the pre-eruption average and posteruption average sea-ice edge.

increase in Arctic sea ice, while no robust signature on Antarctic sea ice characterizes those eruptions that are comparable to historical eruptions. The post-eruption sea-ice evolution in supervolcano simulations can be clearly separated into two phases: an initial one of bipolar expansion and a delayed one marked by the contrast between persisting Arctic expansion and strong Antarctic contraction. The latter constitutes counterintuitive simulated behavior, whose explanation seemingly lies in the anomalous seasonal behavior of a few key regions. This is explored further in the next section.

\subsection{Mechanism of Arctic and Antarctic sea-ice response to a supervolcano eruption}

In this section, we focus on the mechanism(s) behind the seaice response to the SUPER1 eruption during the initial bipolar synchronic phase and the subsequent inter-hemispheric asymmetric phase. The SUPER1 ensemble is chosen among the two supervolcano eruptions since previous studies on the same ensemble (Timmreck et al., 2010, 2012) provide context for our inferences.

Immediately after the eruption, the meridional air temperature gradient temporarily increases in the lower stratosphere (Fig. S3 in the Supplement) due to in situ heating by the volcanic aerosols. As a consequence (see, e.g., Timmreck, 


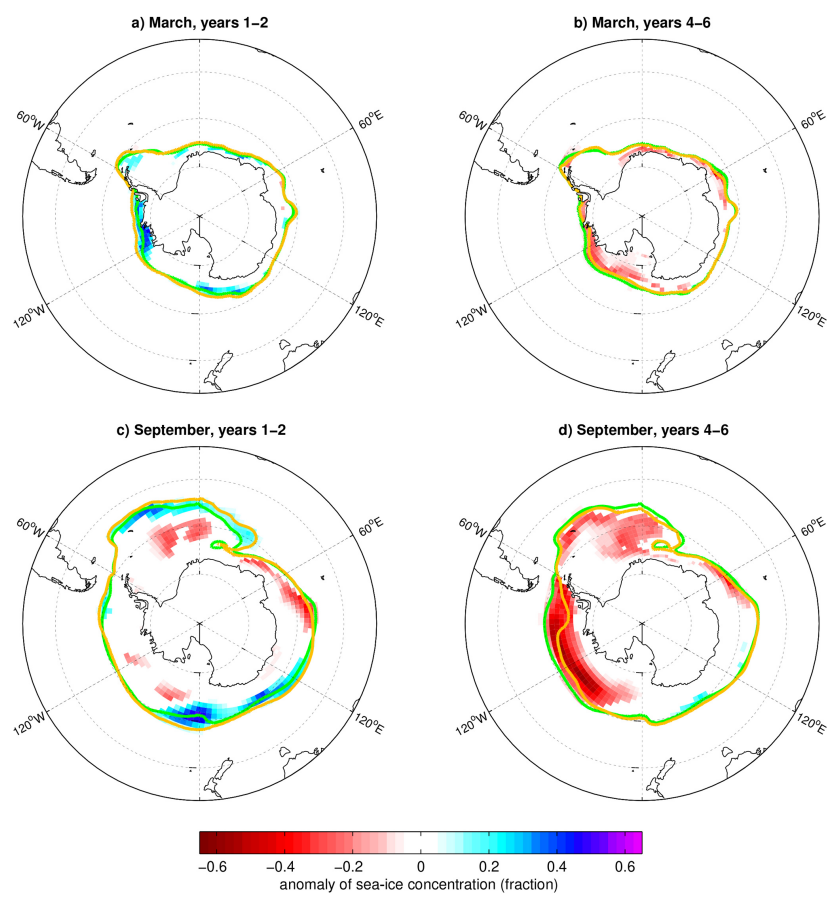

Figure 6. Ensemble-mean simulated March (top panels) and September (bottom panels) Antarctic sea-ice concentration anomalies for integration years 1-2 (a, b) and 4-6 (c, d) of the SUPER1 ensemble. Only grid points where the anomaly is significant at $95 \%$ confidence ( $n=5$; see methods) are shown. The green and orange lines indicate, respectively, the pre-eruption average and posteruption average sea-ice edge.

2012), the stratospheric polar vortex strengthens in both hemispheres until the volcanic cloud dissipates, i.e., for the first two post-eruption years (Fig. S4 in the Supplement). The tropospheric response is dominated by significant cooling, which persists especially in the Northern Hemisphere winter (Fig. S3 in the Supplement), and by weakening of both the Hadley and Ferrell cells (Figs. S5-S6 in the Supplement), which is consistent with a slowdown of the global hydrological cycle (Fig. S7 in the Supplement; also compare Fig. 2b). The weakening of the general circulation is further associated with weakened tropical and midlatitude zonal flow in both hemispheres (Fig. 7b). This is also concomitant with short-lived anomalous eastward polar circulations, which we interpret as part of the downward propagation of the volcanically forced strengthened stratospheric polar vortices. Zonalmean meridional winds at their climatological hemispheric maxima around $30^{\circ} \mathrm{N}$ and $50^{\circ} \mathrm{S}$ also depict a significant reduction of the zonal-mean northward flow in years 1-2 in the Northern Hemisphere (Fig. 7c).

Later on, anomalies in the general atmospheric circulation become less pronounced and are only locally significant, though weaker than normal jet conditions remain apparent (Fig. S4 in the Supplement). Therefore, internal atmospheric processes strongly contribute to the initial response,
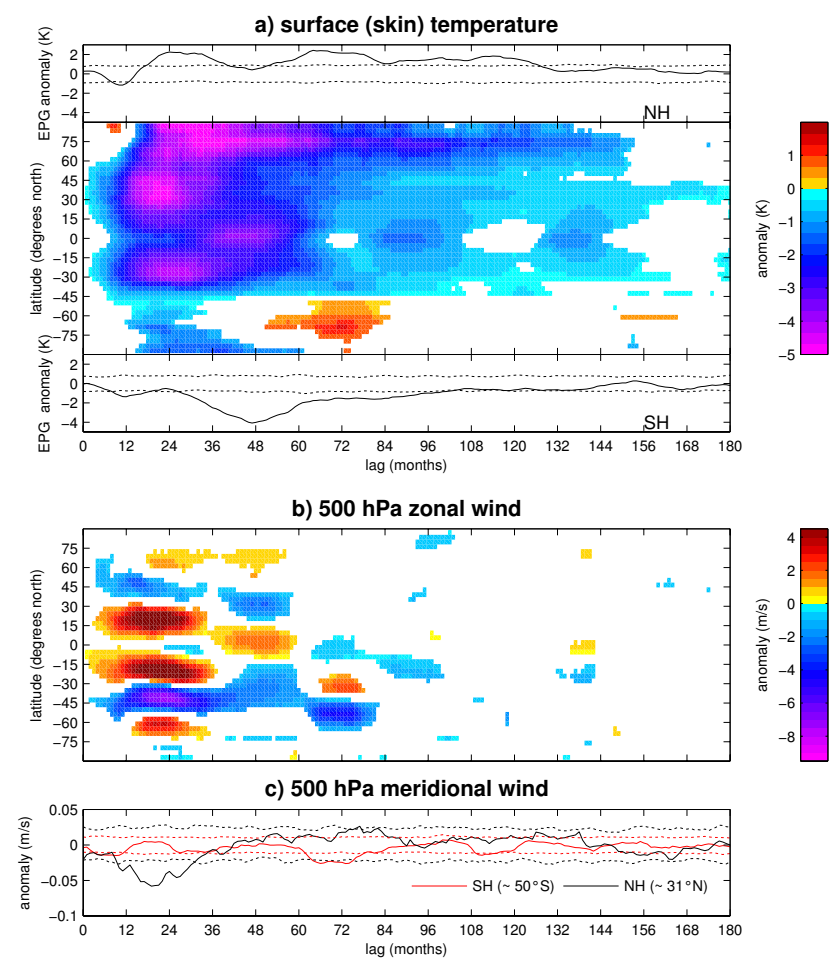

Figure 7. Ensemble-mean post-eruption evolution of zonal-mean surface temperature (a), zonal-mean $500 \mathrm{hPa}$ zonal wind (b) and meridional wind (c) anomalies for the SUPER1 ensemble. Positive zonal and meridional winds are, respectively, eastward and northward. Filled contours in (a, b): Hovmoeller diagrams; only changes statistically significant at $99 \%$ confidence are shown. Line plots in (a): anomalies of equator-to-pole gradient (EPG) for the Northern (top) and Southern (bottom) hemispheres. EPG is defined, for each hemisphere, as the difference between values at the grid latitude closest to the equator and the first grid latitude poleward of $70^{\circ}$. Dotted lines in panels (a,c) are $98 \%$ confidence ranges. A 13-month running-average smoothing has been applied to all data.

whereas climatic signals on the decadal scale are mostly related to oceanic and ocean-atmosphere-coupled processes. This is the case, for example, for the significant though rather small increase of the zonal-mean southward flow in years 5-6 detected in the Southern Hemisphere (Fig. 7c). The structure of vertical profiles of zonal-mean anomalies in atmospheric parameters depicts an overall symmetry between the general atmospheric circulation of Northern and Southern Hemispheres in both phases of post-eruption seaice response (Figs. S3-S11 in the Supplement). The persistent colder tropospheric anomalies over the Arctic, especially during the Northern Hemisphere winter and contrasting with the comparatively weak and short-lived Antarctic anomalies, represent the most apparent inter-hemispheric asymmetry in the post-eruption atmosphere (Fig. S8 in the Supplement).

Significant decadal anomalies characterize the posteruption evolutions of zonal-mean surface temperature and its associated hemispheric meridional gradients (Fig. 7a). 
The post-eruption anomalies depict (i) strong initial cooling, mostly related to quick responses over the landmasses; (ii) bipolar asymmetry in the form of delayed and prolonged (compared to tropical regions) cooling in the Arctic contrasting with the reduced cooling and subsequent warming in the Antarctic; (iii) inter-hemispheric asymmetry in the equator-to-pole temperature gradient, in the form of a temporarily strengthened gradient in the Northern Hemisphere contrasting with a prolonged weakened gradient in the Southern Hemisphere; and (iv) delayed (compared to both tropical and polar regions) cooling in the equatorial band, seemingly phasing ENSO to a La Niña state in year 3. The latter feature is associated with a temporary reduction of meridional gradients, which at this stage feature highly significant negative anomalies in the Southern Hemisphere.

The anomalous atmospheric energy and oceanic heat transports into the polar regions (Fig. 8) provide constraints on our causal interpretation of the diagnosed regional changes. In the Northern Hemisphere, significant (i.e., outside the internal variability range) and prolonged reductions in the meridional heat transport into the Arctic region are diagnosed for both the atmosphere and the ocean: the reduction in atmospheric heat transport peaks at around lag of 24 months and remains at significant levels over a six-year period; oceanic heat transport is reduced below the lower threshold of internal variability around lag of 24 months and persists in an anomalously low state for almost one decade. The estimated dry static atmospheric energy transport remains generally within the internal variability range, with a less clear ensemble-mean evolution compared to the moist static energy transport (Fig. 8a). This indicates that the latent heat component - entailing reduced global ocean losses to the atmosphere (not shown) and reduced global precipitation (Fig. 2b) - dominates the response over the thermal component. At this latitude, the post-eruption anomalous oceanic heat transport is dominated by the gyre component (Fig. 8b), which agrees with the general behavior typically simulated by MPI-ESM-COSMOS-Mill (e.g., Zanchettin et al., 2012, 2013a).

In the Southern Hemisphere, the atmospheric energy transport into the Antarctic region is significantly reduced between about two and eight years after the eruption (Fig. 8c), reflecting the evolution of anomalous equator-to-pole surface temperature gradients (Fig. 7a). In absolute values, the associated peak post-eruption anomaly is about half of its Arctic counterpart (compare panels a and c of Fig. 8). An initial, short-lived response is diagnosed in the estimated dry static atmospheric energy transport, compatible with the surface and tropospheric cooling simulated around these latitudes (compare Fig. 7a), which is evidently compensated for by an increase in the atmospheric latent heat component. Oceanic heat transport into the Antarctic is characterized by strong interannual variability in its post-eruption anomalous evolution as well as by strong internal variability compared to its Arctic counterpart (compare ranges in Fig. 8b, d). As a consequence, despite peak anomalies about twice those diagnosed in the Arctic, the post-eruption ocean heat transport into the Antarctic remains mostly within the internal variability range. The most significant feature is a temporary reduction in the total poleward transport around lag of 48 months (Fig. 8d). As for the Northern Hemisphere, at these latitudes oceanic transport is dominated by the gyre component.

In summary, both polar regions feature a post-eruption decrease in the energy import. However, the decrease is overall more significant for the Arctic due to an overall more constrained oceanic internal variability range and to constructively superposing comparable contributions from the atmosphere and the ocean, the former being pivotal in the initial response phase and the latter dominating the response thereafter. For the Antarctic, both oceanic and moist atmospheric energy transports remain initially unaffected, pointing to dynamical circulation changes as a cause for the initial Antarctic sea-ice response. Furthermore, the relevance of the ocean for the post-eruption Antarctic energy budget and its attribution to the imposed forcing is hampered by its strong internal variability. It is therefore important to relate anomalous ocean meridional heat transports to dynamical changes in the oceanic circulation.

In the Northern Hemisphere, the general response of the oceanic circulation to the SUPER1 eruption is in line with the behavior typically simulated by MPI-ESM-COSMOS-Mill after historical eruptions (see, e.g., Zanchettin et al., 2012, 2013a). We therefore only show changes more closely related to sea ice. The post-eruption reduction in gyre-driven northward heat transport is clearly associated with a weakening of the subpolar gyre and of the North Pacific gyre in the Kuroshio-Oyashio extension region (Fig. 9a). The weak Gulf Stream together with strong anomalous ocean heat losses to the atmosphere contributes to anomalous cold conditions in the upper polar ocean (not shown). The regional cold anomaly sustains the deepening of the ocean mixed layer, which occurs largely in the western portion of the subpolar gyre and in the Irminger and especially Nordic seas (Fig. 10a). Associated processes of deep-water formation result in a progressive intensification of the Atlantic Meridional Overturning Circulation (AMOC) of up to $3 \mathrm{~Sv}$ at $30^{\circ} \mathrm{N}$ and $1000 \mathrm{~m}$ depth, which in turn allows for a delayed temporary increase in the northward ocean heat advection in the tropical and midlatitude band (not shown). Anomalously strong oceanic convection in the Nordic Seas occurs also during the second phase of the post-eruption sea-ice response (Fig. 10b) due to the persistent cold anomaly (compare Fig. 7a). Insulation from the sea-ice edge, which has by now advanced, confines the extent of the deepening region (Fig. 10b), exemplifying how sea-ice evolution is fully embedded within the general coupled atmospheric-oceanic response mechanism. We further note that at this later stage the anomalous patterns of both surface energy fluxes and near-surface atmospheric circulation do not reveal robust large-scale features (patterns not shown), confirming the predominant role (relative to the 

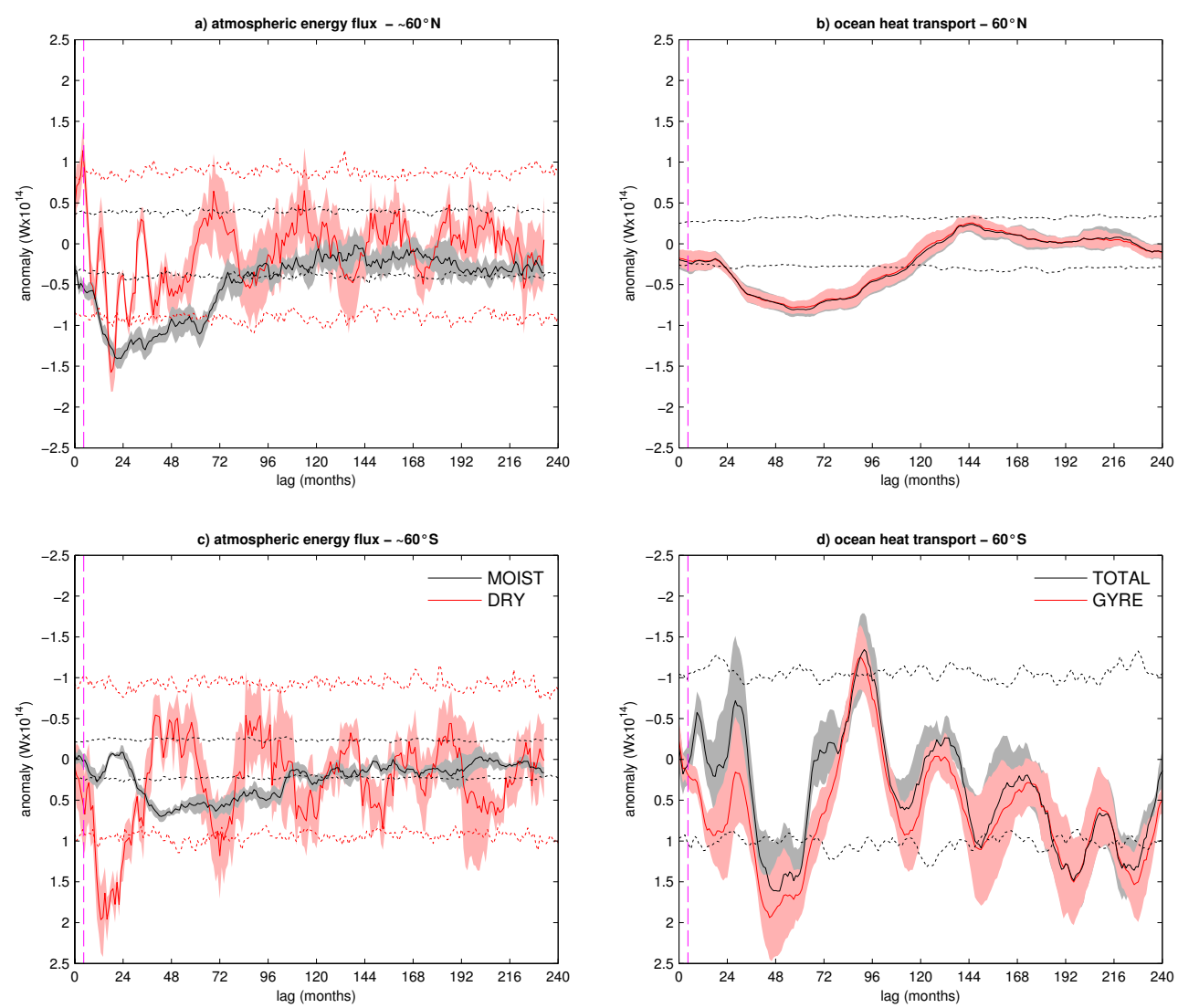

Figure 8. Ensemble-mean simulated anomalies of zonally integrated atmospheric energy transport at $\sim 60^{\circ} \mathrm{N}$ (a) and $\sim 60^{\circ} \mathrm{S}$ (c), and oceanic heat transport by advection at $60^{\circ} \mathrm{N}(\mathbf{b})$ and at $60^{\circ} \mathrm{S}$ (d) for the SUPER 1 ensemble. Lines and shading represent the mean anomaly and the standard error of the mean respectively. Dashed lines indicate the internal variability range ( $n=5$; see methods). Internal variability ranges for the gyre component of ocean heat transport are not shown, since they are barely distinguishable from that of the total transport. The dashed vertical magenta line indicates the approximate start of the eruptions. Lag(0) corresponds to January of the eruption year. Anomalies are smoothed with a 13-month centered moving average. Positive values correspond to northward transport anomalies ( $y$ axis is inverted in panels (c) and (d)) to ease the comparison of poleward transports in the two hemispheres.

atmosphere) of the anomalous decadal oceanic evolution for sustaining the post-eruption Arctic sea-ice anomaly.

In the Southern Hemisphere, the initial Antarctic seaice response is a dynamical consequence of a strengthened circumpolar westerly circulation along the sea-ice margins. This feature is especially evident in austral winter (Fig. 11b), when it describes a poleward shift of the midlatitude westerlies partly superposed on a positive phase of the Southern Annular Mode. In summer, the pattern describes a weakening of both polar and midlatitude flow (Fig. 11d) typical of a negative phase of the Southern Annular Mode. The marked seasonality in the near-surface wind response goes along with the marked seasonality diagnosed in the sea-ice area response (Figs. $4 \mathrm{~b}$ and $6 \mathrm{a}, \mathrm{c}$ ). Our interpretation is therefore consistent with the enhanced connectivity of observed sea-ice variability with the overlying atmospheric circulation associated with large-scale modes like the Southern Annular Mode and ENSO (Simpkins et al., 2012). Disentangling the different contributions to the post-eruption polar circulation in the southern-hemispheric lower troposphere would require a study dedicated to this topic. We only remark on the importance of the antagonism between the thermal (i.e., meridional gradient in surface cooling, Fig. 7a) and dynamical (i.e., downward propagation of strengthened stratospheric polar vortex) effects. The Antarctic Circumpolar Current (ACC) weakens (Fig. 9c) in response to the weakened (in summer) and southward shifted (in winter) circumpolar midlatitude westerly flow (Figs. $7 \mathrm{~b}$ and $11 \mathrm{~b}, \mathrm{~d}$ ). During this initial response phase, the ocean also undergoes important dynamical modifications at the regional scale. In particular, the September sea-ice concentration decreases locally in the sea-ice interior region of the outer Weddell Sea (Fig. 6c). This area features significantly strengthened ocean energy losses to the atmosphere (Fig. 11c) that are related to a significant deepening of the mixed layer (Fig. 10c) and hence penetration of the post-eruption cold anomaly into the deep ocean layers. Of course, the causal chain linking these features cannot be depicted without the support of dedicated 

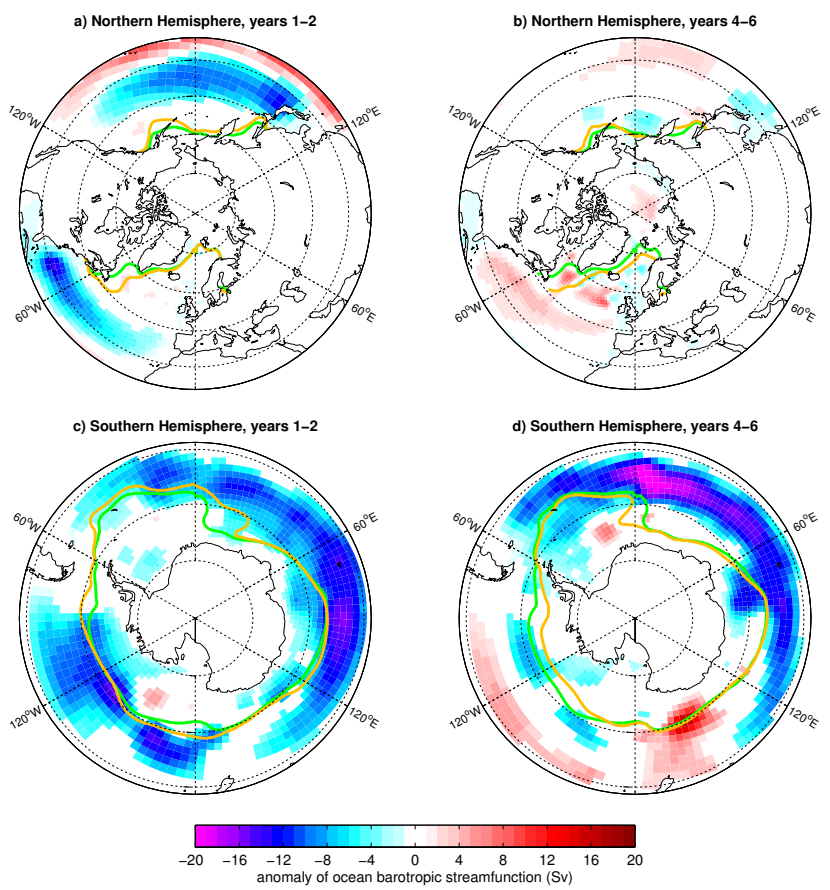

Figure 9. Ensemble-mean simulated annual-average oceanic barotropic stream function for integration years 1-2 (a, b) and 4-6 (c, d) of the SUPER1 ensemble. Only changes statistically significant at $95 \%$ confidence are shown. The green and orange lines indicate, respectively, the pre-eruption and post-eruption average winter (top: DJF; bottom: JJA) sea-ice edge.

sensitivity experiments. Such a response is not diagnosed within the ice-covered region of the Ross Sea despite local strengthening of ocean heat losses (Fig. 11c).

Local feedbacks involving sea-ice area, turbulent heat fluxes and modified atmospheric circulation complete the explanation for the diagnosed sea-ice behavior during the second phase of Southern Hemisphere's sea-ice response. We note particularly the anomalous equatorward near-surface atmospheric flows off the West Antarctica coast in austral summer (Fig. 12b) and in the outer Ross Sea in austral winter (Fig. 12d), which are associated with local negative surface energy flux anomalies over extensive regions (Fig. 12a, c). The local anomalous near-surface winds set in under a significantly weakened midlatitude westerly circulation, especially during austral summer (Fig. 12b). The anomalous nearsurface wind pattern contrasts the zonal-average tendency in the mid-troposphere (Fig. 7c) and is consistent with a net reduction of atmospheric energy import into the Antarctic region (Fig. 8c). The latter should therefore be regarded as mainly a consequence of local coupled ocean-atmosphere dynamics internal to the Antarctic region. The consistency with corresponding anomalous patterns in the SUPER2 ensemble (not shown) adds support to this interpretation.
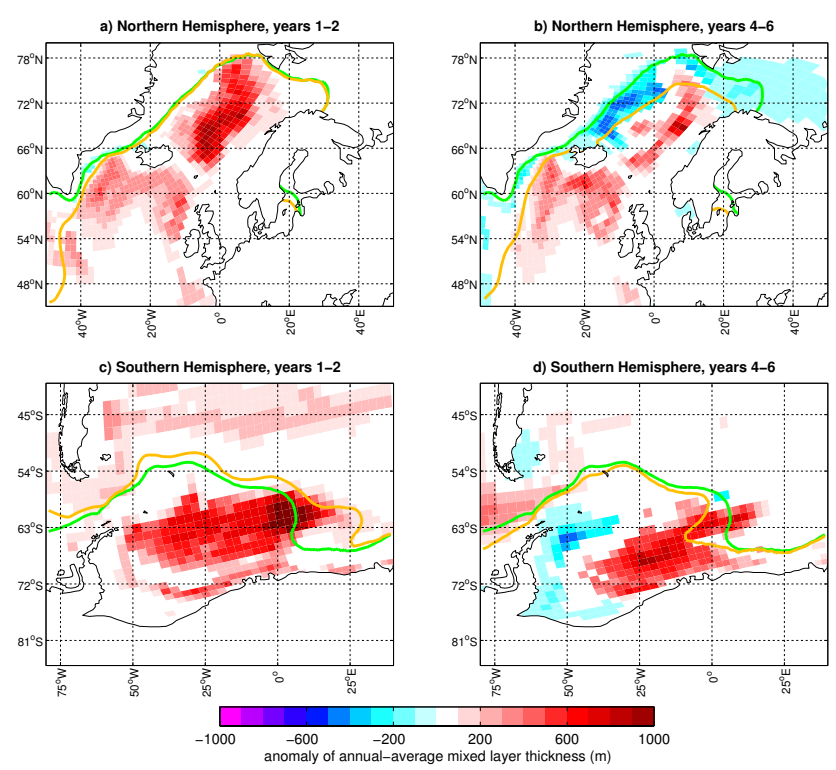

Figure 10. Ensemble-mean simulated annual-average mixed layer thickness in two oceanic deep convection regions for integration years 1-2 (a, b) and 4-6 (c, d) of the SUPER1 ensemble. Only changes statistically significant at $95 \%$ confidence are shown. The green and orange lines indicate, respectively, the pre-eruption and post-eruption average winter (top: DJF; bottom: JJA) sea-ice edge.

Enhanced deep convection still takes place in the Weddell Sea region during the second response phase (Fig. 10d), though its magnitude and extent are reduced compared to the initial anomaly. Again, the causal chain for this behavior cannot be fully clarified based on our experiments alone allowing for tentative hypotheses only. We accordingly interpret the strengthened oceanic convection as a likely consequence of locally strengthened surface exchange processes (Fig. 12c) favored by the winter sea-ice area (Fig. 6d), which has at this stage decreased. We thus regard the negative sea-ice anomaly as the closure element of the feedback mechanism characterizing the post-eruption ocean-atmosphere evolution in the Weddell Sea region (i.e., the regional anomaly persists until the anomalous large-scale atmospheric circulation sustains a local sea-ice reduction).

\section{Summarizing discussion}

In this study we used ensemble climate simulations performed with the COSMOS-Mill version of the Max Planck Institute Earth System Model (MPI-ESM) to investigate the decadal response of Arctic and Antarctic sea ice to volcanic perturbations. We considered volcanic eruptions of different magnitude, ranging from eruptions comparable to historical ones to supervolcano-size eruptions, the latter with different characteristics, including tropical and extra-tropical locations. In all ensembles a sustained, largely thermally driven expansion is robustly simulated for total area and volume of 

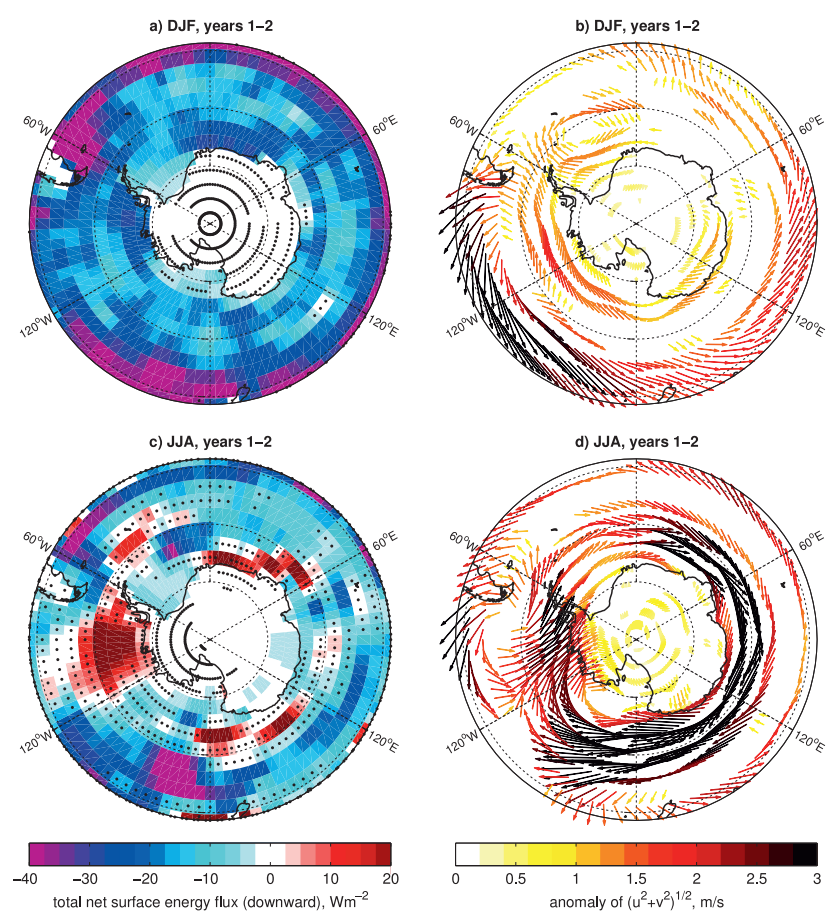

Figure 11. Ensemble-mean simulated Southern Hemisphere summer (DJF, top) and winter (JJA, bottom) total net surface energy flux (latent and sensible heat, short- and long-wave radiation, a, c) and $10 \mathrm{~m}$ wind anomalies (b, d) for integration years 1-2 of the SUPER1 ensemble. (a, c): black dots indicate grid points where changes are nonsignificant at the $95 \%$ confidence level; (b, d): only changes statistically significant at $95 \%$ confidence for at least one of the wind components are shown.

Arctic sea ice. Amplitude and duration of the anomalies essentially depend on the magnitude of the imposed forcing. In contrast, the simulated response of Antarctic sea ice is elusive in the case of the eruptions that are comparable to historical ones, while supervolcano eruptions induce an initial, short-lived, mostly dynamically driven Antarctic sea-ice expansion which is followed by a prolonged retraction phase. For both historical and supervolcano eruption types we diagnose, therefore, an inter-hemispheric asymmetry in the simulated post-eruption decadal evolution of sea ice.

In the case of a supervolcano eruption, the asymmetry primarily derives from the different sensitivity of Arctic and Antarctic regional climates to the induced global energy imbalance and from the associated large-scale atmospheric and oceanic dynamical reactions. Thermodynamics is the key for the Arctic sea-ice expansion, which is triggered by the initially reduced atmospheric heat import and is then sustained on a decadal timescale by the oceanic heat import, by then reduced. Noteworthy decadal responses of North AtlanticArctic large-scale oceanic circulation are qualitatively similar for historical and supervolcano eruptions, both including a delayed strengthening of the AMOC and a northwestward compression of the subpolar gyre (compare Fig. 9b
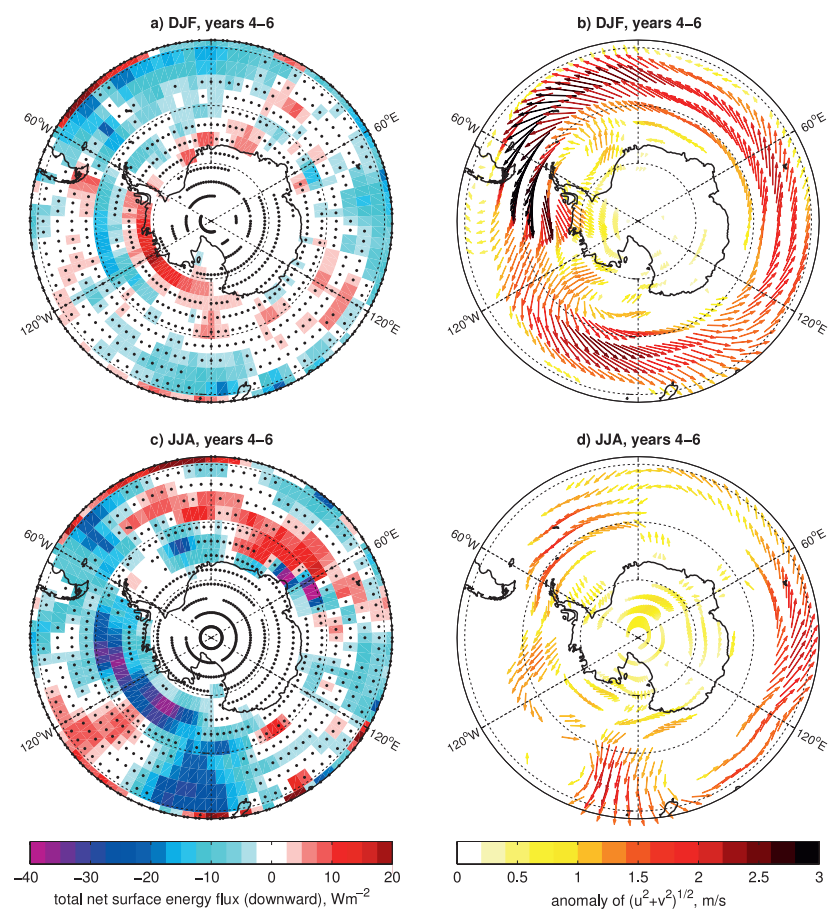

Figure 12. Ensemble-mean simulated Southern Hemisphere summer (DJF, top) and winter (JJA, bottom) total net surface energy flux (latent and sensible heat, short- and long-wave radiation, a, c) and $10 \mathrm{~m}$ wind anomalies (b, d) for integration years 4-6 of the SUPER1 ensemble. (a, c): black dots indicate grid points where changes are nonsignificant at the $95 \%$ confidence level; (b, d): only changes statistically significant at $95 \%$ confidence for at least one of the wind components are shown.

with Zanchettin et al., 2012). For the supervolcano eruptions, however, the post-eruption drop in the heat content of the global upper ocean is too large to allow for circulation-driven positive anomalies of ocean heat transport into the Arctic, as diagnosed for historical eruptions (see Zanchettin et al., 2012, 2013a).

In contrast to Arctic sea ice, Antarctic sea ice, in the shortterm, reacts mostly to dynamical atmospheric changes initiated by the volcanically induced strengthening of the Southern Hemisphere's stratospheric polar vortex. Antarctic sea ice is thereafter implicated in local surface energy exchange processes dominating the response diagnosed at the hemispheric scale. The post-eruption anomalies of lateral oceanic heat flux are larger in the Antarctic than in the Arctic, but they only temporarily exceed the internal variability range (Fig. 8d). We regard the temporarily significantly decreased poleward oceanic heat transport around year 4 as a marginal contributor to the Antarctic sea-ice anomaly (negative at this stage). Post-eruption negative anomalies of atmospheric energy fluxes are likely a consequence rather than a cause of the chain of local feedbacks within the Antarctic region. The substantially different exposure of the Arctic and Antarctic regional climates to volcanically forced energy imbalances 
explains why the inter-hemispheric asymmetry becomes apparent with increasing magnitude of the eruption.

In both the Arctic and the Antarctic, the regions with the strongest simulated sea-ice response correspond to key regions for sea-ice and ice-cap variability found in reconstructions and observations. For instance, extensive increases in September Arctic sea-ice concentrations are simulated in the Canadian Arctic Archipelago and in Baffin Bay (Fig. 5c). This is in agreement with records of ice-cap growth from Arctic Canada covering the last millennium and indicating a strong link with large volcanic eruptions (Anderson et al., 2008; Miller et al., 2012). In our simulations, internal variability of Antarctic sea ice is stronger for total area and weaker for total volume compared to Arctic sea ice (Fig. 3; note that total Antarctic sea-ice volume is almost half its Arctic counterpart). As shown by the forced responses, hemispheric metrics for the Antarctic often mask strong, spatially heterogeneous variability (Fig. 6c), as also indicated by observations (e.g., Simpkins et al., 2012, 2013). The interplay between large-scale dynamics and local processes highlights several relevant mechanisms and features, which need to be reliably represented in models to build confidence in the simulated representation of post-eruption sea-ice evolutions, particularly for the Antarctic. These include, among others, the global hydrological cycle, the downward propagation of polar vortex signals, ENSO, the global oceanic conveyor of heat and the atmospheric forcing of the Antarctic circumpolar current (ACC).

The downward propagation of volcanically forced stratospheric signals, especially the post-eruption strengthening of the stratospheric polar vortex, is important for the initial dynamical atmospheric response to explosive volcanic eruptions (e.g., Stenchikov et al., 2006; Fischer et al., 2007; Zanchettin et al., 2012). The stratospheric polar vortex significantly strengthens after the eruption in both hemispheres in HIST2, SUPER1 (Fig. S4 in the Supplement) and SUPER2, with duration tracing that of the imposed radiative anomaly, but it does not in HIST1 (not shown). Signals in the polar mid-troposphere are robust only for supervolcano eruptions (compare Fig. 7b). Larger ensembles could determine whether the lack of robust dynamical atmospheric responses for historical eruptions reflects a low signal-tonoise ratio rather than a true lack of dynamical response. The latter hypothesis, however, is supported by the deficient representation of stratospheric dynamics and stratospherictropospheric coupling in latest-generation "low-top" coupled general circulation models (CGCMs) (Charlton-Perez et al., 2013; Omrani et al., 2014), a characteristic which is shared by the version of MPI-ESM used here.

Similar concerns arise about the simulated southern tropospheric midlatitude jet, e.g., its climatological position too close to the equator (e.g., Swart and Fyfe, 2012). Furthermore, simulated Antarctic sea-ice variability and sensitivity to external disturbances may also suffer from an imperfect description of tropospheric internal dynamics, e.g., those re- lated to variability in the Southern Annular Mode (Simpson et al., 2012) and of the associated surface wind variability (Zhang, 2013). In particular, the strength and latitudinal position of the circumpolar winds affect the Antarctic sea ice via the Ekman transport (Maksym et al., 2012; Landrum et al., 2012; Weijer et al., 2012). In our simulations the total Antarctic sea-ice volume does not support the early posteruption horizontal expansion phase (Fig. 3b, d) leading to sea-ice thinning. This contrasts other model-based indications that wind intensification tends to increase Antarctic seaice volume through increased ridged ice production (Zhang, 2014). The post-eruption initial resilience of total Antarctic sea-ice volume may therefore reflect a truly distinct dynamical behavior related to extremely strong volcanic forcing, but it may also reflect poor representation of near-surface atmospheric circulation. This is important for the case discussed here, given also the marked seasonal character of Antarctic sea-ice response to the volcanic perturbation during the delayed contraction phase (Fig. 4d).

The timing of the strongest post-eruption surface cooling at equatorial latitudes, delayed with respect to that at midlatitudes, strongly contributes to the post-eruption strengthening of meridional gradients (Fig. 7). This equatorial cooling has a strong imprint in the Pacific in the form of an apparent phasing of ENSO on a delayed La Niña state. This robust response of ENSO to the volcanic perturbation occurs after the maximum global surface cooling (compare with Fig. 2a), when the Toba/SUPER1 ensemble indicates a nonsignificant, though tendentially warm, ENSO response (Timmreck et al., 2010). ENSO in this version of MPI-ESM was consistently found to be only weakly sensitive to volcanic forcing for a selection of eruptions comparable to historical ones in transient climate simulations covering the last millennium, with an only tendential response towards a cold (La Niña) anomaly (Zanchettin et al., 2012). Nonetheless, two considerations limit our confidence regarding the simulated forced behavior of ENSO. First, ENSO's representation is still a challenge for coupled climate models (e.g., Guilyardi et al., 2009) and MPI-ESM-COSMOS-Mill produces ENSO fluctuations that are too strong and too regular (compare Jungclaus et al., 2006). Second, while observations are still insufficient to draw confident conclusions about the role of ENSO in post-eruption dynamics of tropical and extra-tropical climates, a recent reconstruction points to a robust ENSO response to the largest historical tropical eruptions, consisting of immediate cooling followed by anomalous warming one year after (J. Li et al., 2013). The disagreement between indications from this paleoclimate record and from MPI-ESMCOSMOS-Mill simulations asks for additional dynamical investigations that are beyond the scope of this study.

The strength of the ACC is overestimated in MPI-ESMCOSMOS-Mill (Marsland et al., 2003; compare also: Jungclaus et al., 2013). Implications for the diagnosed posteruption Antarctic sea-ice evolutions and for the global redistribution of ocean heat anomalies are difficult to disentangle 
without dedicated sensitivity experiments. We note, however, that an overly strong and displaced ACC corresponds to a biased structure and strength of the subpolar gyres and of associated oceanic convective activity. In fact, the ocean model MPIOM largely overestimates the mixed layer depth in the Ross Sea and Weddell Sea gyres (Griffies et al.., 2009). The Weddell Sea gyre is associated with the occurrence of a small permanent polynya (Marsland et al., 2003). Biases of this kind could be relevant for the delayed reduction diagnosed in Antarctic sea ice (Fig. 6d) as well as for the propagation of heat anomalies into the deep ocean (Fig. 11c, d). As shown by different models, ocean/sea-ice mechanisms during the sea-ice growth phase are strongly interrelated with oceanic stratification and ocean vertical heat transport. In a weakly stratified Southern Ocean, ice melting from ocean heat flux decreases faster than ice growth, leading to an increase in net ice production and hence an increase in ice mass (Zhang, 2007). In the Community Climate System Model version 3 , the freshwater flux between Antarctic sea ice and the Southern Ocean is closely intertwined with ocean convection and deep-ocean heat uptake (Kirkman and Bitz, 2011). On the one hand, a (climatologically) excessively mixed Southern Ocean, as in MPIOM (Griffies et al.., 2009), implies reduced efficiency of external forcings to produce anomalous heat fluxes. On the other hand, locally excessive convective strength as in the Weddell Sea would imply enhanced oceanic heat losses to the atmosphere. Consequently, simulated estimates of post-eruption global air-surface cooling (e.g., Timmreck et al., 2010) may be biased towards being too conservative.

A link exists between the internally generated multidecadal- and centennial-scale variability of the Weddell Sea sea-ice cover and of the AMOC in the Kiel Climate Model (Park and Latif, 2008), where oceanic deep convection within the Weddell Sea gyre plays a central role in the inter-hemispheric connection (Martin et al., 2013). Ascribing a similar bipolar ocean seesaw to the decadal-scale volcanically forced evolutions presented here, one would expect that the enhanced deep convection in the Weddell Sea (Fig. 11c, d) hampers the southward deep-water flow in the North Atlantic, i.e., promotes an AMOC slowdown. Overly strong ocean convection in the Weddell Sea could accordingly help explain the overall weaker post-eruption AMOC strengthening in MPI-ESM-COSMOS-Mill compared to other CGCMs, as discussed in Zanchettin et al. (2012). We note nonetheless that this has likely only faint implications for the post-eruption decadal Arctic sea-ice evolution, since the northward oceanic heat transport at subpolar and polar latitudes is largely determined by the gyre circulation (Fig. 8b; see also Zanchettin et al., 2012, 2013a).

Perturbation experiments like the supervolcano experiments described here highlight known limits and less understood features of CGCMs and earth system models, and might therefore help to delimit the reliability of their forced dynamical climate responses in more general contexts. We foresee several advantages in a more extensive employment of supervolcano simulations as an analog of, e.g., sudden warming experiments. The restoration from the induced cold anomaly highlights variability modes and teleconnections that would arise under background warming conditions due predominantly to internal climate variability, whereas externally forced warming experiments produce forced anomalous patterns of climate variability. We remark on the fact that our five-member Toba simulation ensemble was sufficient to yield largely significant, and hence coherent, dynamical responses. Thus, such a small-size ensemble allows for confident inferences about simulated forced global (Timmreck et al., 2010) as well as regional (Timmreck et al., 2012) changes. As shown here, supervolcano experiments allow us to gain insights regarding the relative importance of the thermodynamical and dynamical components of sea-ice responses to imposed negative net radiative imbalances. Such separation highlights differences in the internal hemispheric dynamics related to external radiative perturbations.

\section{Conclusions}

Ensemble earth system model simulations depict interhemispheric differences in the decadal sea-ice response to strong volcanic eruptions regarding both the sensitivity to the forcing and the sign of the induced anomalies. Arctic sea ice is very sensitive to volcanic forcing owing especially to its strong exposure to externally forced changes in meridional heat transport. By contrast, Antarctic sea ice appears to be less susceptible to volcanic forcing and responds only to extremely large (so-called supervolcano) eruptions. In further contrast to Arctic sea ice, the post-eruption evolution of Antarctic sea ice is mostly determined by feedbacks that set in within the Antarctic region. Whereas Arctic sea ice robustly expands for a prolonged period after major volcanic eruptions, the post-eruption Antarctic sea-ice evolution includes an initial short-lived expansion and a subsequent prolonged contraction phase. This sea-ice asymmetry reflects the potential of volcanic forcing to significantly affect interhemispheric interannual to decadal climate variability in a broader context. Nonetheless, key processes implied in the generation of the asymmetry include less understood and hence poorly simulated features. This poses non-negligible caveats when extrapolating simulation-based inferences to the real climate system. In this sense, idealized supervolcano perturbation experiments could serve the assessment of climate models' performances under strong forcing conditions.

\section{The Supplement related to this article is available online at doi:10.5194/esd-5-223-2014-supplement.}


Acknowledgements. The authors thank Achim Stössel for the helpful discussions and comments on an earlier version of the manuscript and Kay Huebner for the stimulating initial analyses. Comments from two anonymous reviewers helped improve the clarity of the manuscript. This work benefitted from the MPI-M integrated projects "Millennium" and "Super Volcano". This work was supported by the Federal Ministry for Education and Research in Germany (BMBF) through the research program "MiKlip" (FKZ:01LP1158A(DZ):/01LP1130A(CT)). The MPI-ESM simulations were conducted at the German Climate Computing Center (DKRZ).

The service charges for this open access publication have been covered by the Max Planck Society.

Edited by: J. C. Hargreaves

\section{References}

Ahmed, M., Anchukaitis, K. J., Asrat, A., Borgaonkar, H. P., Braida, M., Buckley, B. M., Büntgen, U., Chase, B. M., Christie, D. A., Cook, E. R., Curran, M. A. J., Diaz, H. F., Esper, J., Fan, Z., Gaire, N. P., Ge, Q., Gergis, J., González-Rouco. J. F., Goosse, H., Grab, S. W., Graham, N., Graham, R., Grosjean, M., Hanhijärvi, S. T., Kaufman, D. S., Kiefer, T., Kimura, K., Korhola, A. A., Krusic, P. J., Lara, A., Lézine, A., Ljungqvist, F. C., Lorrey, A. M., Luterbacher, J., Masson-Delmotte, V., McCarroll, D., McConnell, J. R., McKay, N. P., Morales, M. S., Moy, A. D., Mulvaney, R., Mundo, I. A., Nakatsuka, T., Nash, D. J., Neukom, R., Nicholson, S. E., Oerter, H., Palmer, J. G., Phipps, S. J., Prieto, M. R., Rivera, A., Sano, M., Severi, M., Shanahan, T. M., Shao, X., Shi, F., Sigl, M., Smerdon, J. E., Solomina, O. N., Steig, E. J., Stenni, B., Thamban, M., Trouet, V., Turney, C. S. M., Umer, M., van Ommen, T., Verschuren, D., Viau, A. E., Villalba, R., Vinther, B. M., von Gunten, L., Wagner, S., Wahl, E. R., Wanner, H., Werner, J. P., White, J. W. C., Yasue, K., and Zorita, E.: Continental-scale temperature variability during the past two millennia, Nat. Geosci., 6, 339-346, doi:10.1038/NGEO1797, 2013.

Anderson, R. K., Miller, G. H., Briner, J. P., Lifton, N. A., and DeVogel, S. B.: A millennial perspective on Arctic warming from $14 \mathrm{C}$ in quartz and plants emerging from beneath ice caps, Geophys. Res. Lett., 35, L01502, doi:10.1029/2007GL032057, 2008.

Barlyaeva, T. V., Mironova, I. A., and Ponyavin, D. I.: Nature of decadal variations in the climatic data of the second half of the 20th century, Dokl. Earth. Sci., 425A, 419-423, 2009.

Beitsch, A., Jungclaus, J. H., and Zanchettin, D.: Patterns of decadal-scale Arctic warming events in simulated climate, Clim. Dynam., doi:10.1007/s00382-013-2004-5, in press, 2013.

Bitz, C. M. and Polvani, L. M.: Antarctic climate response to stratospheric ozone depletion in a fine resolution ocean climate model, Geophys. Res. Lett., 39, L20705, doi:10.1029/2012GL053393, 2012.

Bothe, O., Jungclaus, J. H., Zanchettin, D., and Zorita, E.: Climate of the last millennium: ensemble consistency of simulations and reconstructions, Clim. Past, 9, 1089-1110, doi:10.5194/cp9-1089-2013, 2013.
Brohan, P., Kennedy, J. J., Harris, I., Tett, S. F. B., and Jones, P. D. Uncertainty estimates in regional and global observed temperature changes: a new dataset from 1850, J. Geophys. Res., 111, D12106, doi:12110.11029/12005JD006548, 2006.

Charlton-Perez, A. J., Baldwin, M. P., Birner, T., Black, R. X., Butler, A. H., Calvo, N., Davis, N. A., Gerber, E. P., Gillett, N., Hardiman, S., Kim, J., Krüger, K., Lee, Y.-Y., Manzini, E., McDaniel, B. A., Polvani, L., Reichler, T., Shaw, T. A., Sigmond, M., Son, S.-W., Toohey, M., Wilcox, L., Yoden, S., Christiansen, B., Lott, F., Shindell, D., Yukimoto, S., and Watanabe, S.: On the lack of stratospheric dynamical variability in low-top versions of the CMIP5 models, J. Geophys. Res., 118, 2494-2505, doi:10.1002/jgrd.50125, 2013.

Chylek, P., Folland, C. K., Lesins, G., and Dubey, M. K.: Twentieth century bipolar seesaw of the Arctic and Antarctic surface air temperatures, Geophys. Res. Lett., 37, L08703, doi:10.1029/2010GL042793, 2010.

Crowley, T. J. and Unterman, M. B.: Technical details concerning development of a $1200 \mathrm{yr}$ proxy index for global volcanism, Earth Syst. Sci. Data, 5, 187-197, doi:10.5194/essd-5-187-2013, 2013.

Crowley, T. J., Zielinski, G., Vinther, B., Udisti, R., Kreutz, K., Cole-Dai, J., and Castellano, E.: Volcanism and the little ice age, PAGES News, 16, 22-23, 2008.

Duncan, R. P., Fenwick, P., Palmer, J. G., McGlone, M. S., and Turney, C. S. M.: Non-uniform interhemispheric temperature trends over the past 550 years, Clim. Dynam., 35, 1429-1438, doi:10.1007/s00382-010-0794-2, 2010.

Fernández-Donado, L., González-Rouco, J. F., Raible, C. C., Ammann, C. M., Barriopedro, D., García-Bustamante, E., Jungclaus, J. H., Lorenz, S. J., Luterbacher, J., Phipps, S. J., Servonnat, J., Swingedouw, D., Tett, S. F. B., Wagner, S., Yiou, P., and Zorita, E.: Large-scale temperature response to external forcing in simulations and reconstructions of the last millennium, Clim. Past, 9, 393-421, doi:10.5194/cp-9-393-2013, 2013.

Fischer, E., Luterbacher, J., Zorita, E., Tett, S. F. B., Casty, C., and Wanner, H.: European climate response to tropical volcanic eruptions over the last half millennium, Geophys. Res. Lett., 34, L05707, doi:10.1029/2006GL027992, 2007.

Gillett, N. P. and Thompson, D. W. J.: Simulation of Recent Southern Hemisphere Climate Change, Science, 302, 273-275, doi:10.1126/science.1087440, 2003.

Graf, H. F. and Zanchettin, D.: Central Pacific El Niño, the "subtropical bridge" and Eurasian Climate, J. Geophys. Res., 117, D01102, doi:10.1029/2011JD016493, 2012.

Griffies, S. M., Biastoch, A., Böning, C., Bryan, F., Danabasoglu, G., Chassignet, E. P., England, M. H., Gerdes, R., Haak, H., Hallberg, R. W., Hazeleger, W., Jungclaus, J., Large, W. G., Madec, G., Pirani, A., Samuels, B. L., Scheinert, M., Gupta, A. S., Severijns, C. A., Simmons, H. L., Treguier, A. M., Winton, M., Yeager, S., and Yin, J.: Coordinated Ocean-ice Reference Experiments (COREs), Ocean. Modell., 26, 1-46, doi:10.1016/j.ocemod.2008.08.007, 2009.

Guilyardi, E., Wittenberg, A., Fedorov, A., Collins, M., Wang, C. Z., Capotondi, A., van Oldenborgh, G. J., and Stockdale, T.: Understanding El Niño in ocean-atmosphere General Circulation Models: Progress and challenges, B. Am. Meteorol. Soc., 90, 325$340,2009$. 
Henriksson, S. V., Räisänen, P., Silén, J., and Laaksonen, A.: Quasiperiodic climate variability with a period of 5080 years: Fourier analysis of measurements and Earth System Model simulations, Clim. Dynam., 39, 7-8, 1999-2011, doi:10.1007/s00382-012-1341-0, 2012.

Heuzé, C., Heywood, K. J., Stevens, D. P., and Ridley, J. K.: Southern Ocean bottom water characteristics in CMIP5 models, Geophys. Res. Lett., 40, 1409-1414, doi:10.1002/grl.50287, 2013.

Holden, P. B., Edwards, N. R., Wolff, E. W., Lang, N. J., Singarayer, J. S., Valdes, P. J., and Stocker, T. F.: Interhemispheric coupling, the West Antarctic Ice Sheet and warm Antarctic interglacials, Clim. Past, 6, 431-443, doi:10.5194/cp-6-431-2010, 2010.

Jones, G. S., Gregory, J. M., Stott, P. A., Tett, S. F. B., and Thorpe, R. B.: An AOGCM simulation of the climate response to a volcanic super-eruption, Clim. Dynam., 25, 725-738, 2005.

Jungclaus, J. H., Keenlyside, N., Botzet, M., Haak, H., Luo, J. J., Latif, M., Marotzke, J., Mikolajewicz, U., and Roeckner, F.: Ocean circulation and tropical variability in the coupled model ECHAM5/MPI-OM, J. Climate, 19, 3952-3972, 2006.

Jungclaus, J. H., Lorenz, S. J., Timmreck, C., Reick, C. H., Brovkin, V., Six, K., Segschneider, J., Giorgetta, M. A., Crowley, T. J., Pongratz, J., Krivova, N. A., Vieira, L. E., Solanki, S. K., Klocke, D., Botzet, M., Esch, M., Gayler, V., Haak, H., Raddatz, T. J., Roeckner, E., Schnur, R., Widmann, H., Claussen, M., Stevens, B., and Marotzke, J.: Climate and carbon-cycle variability over the last millennium, Clim. Past, 6, 723-737, doi:10.5194/cp-6723-2010, 2010.

Jungclaus, J. H., Fischer, N., Haak, H., Lohmann, K., Marotzke, J., Matei, D., Mikolajewicz, U., Notz, D., and von Storch, J. S.: Characteristics of the ocean simulations in MPIOM, the ocean component of the MPI-Earth system model, J. Adv. Model. Earth Syst., 5, 422-446, doi:10.1002/jame.20023, 2013.

Karpechko, A. Y., Gillett, N. P., Dall'Amico, M., and Gray, L. J.: Southern Hemisphere atmospheric circulation response to the El Chichón and Pinatubo eruptions in coupled climate models, Q. J. Roy. Meteorol. Soc., 136, 1813-1822, doi:10.1002/qj.683, 2010.

Keith, D. W.: Meridional energy transport: uncertainty in zonal means, Tellus, 47A, 30-44, 1995.

King, J.: Climate science: A resolution of the Antarctic paradox, Nature, 505, 491-492, doi:10.1038/505491a, 2014.

Kinnard, G., Zdanowicz, C. M., Fisher, D. A., Isakkson, E., de Vernal, A., and Thompson, L. G.: Reconstructed changes in Arctic sea ice over the past 1,450 years, Nature, 479, 509-513, doi:10.1038/nature10581, 2011.

Kirkman, C. and Bitz, C. M.: The Effect of the Sea Ice Freshwater Flux on Southern Ocean Temperatures in CCSM3: Deep Ocean Warming and Delayed Surface Warming, J. Climate, 24, 22242237, doi:10.1175/2010JCLI3625, 2011.

Koldunov, N. V., Stammer, D., and Marotzke, J.: Present-Day Arctic Sea Ice Variability in the Coupled ECHAM5/MPI-OM Model, J. Climate, 23, 2520-2543, doi:10.1175/2009JCLI3065.1, 2010.

Landrum, L., Holland, M. M., Schneider, D. P., and Hunke, E.: Antarctic Sea Ice Climatology, Variability, and Late TwentiethCentury Change in CCSM4, J. Climate, 25, 4817-4838, doi:10.1175/JCLI-D-11-00289.1, 2012.

Li, C., Notz, D., Tietsche, S., and Marotzke, J.: The Transient versus the Equilibrium Response of Sea Ice to Global Warming, J. Climate, 26, 5624-5636, doi:10.1175/JCLI-D-12-00492.1, 2013.
Li, J., Xie, S.-P., Cook, E. R., Morales, M. S., Christie, D. A., Johnson, N. C., Chen, F., D'Arrigo, R., Fowler, A. M., Gou, X., and Fang, K.: El Niño modulations over the past seven centuries, Nature Cl. Ch., 3, 822-826, doi:10.1038/NCLIMATE1936, 2013.

Maksym, T., Stammerjohn, S. E., Ackley, S., and Massom, R.: Antarctic sea ice - A polar opposite?, Oceanography, 25, 140151, doi:10.5670/oceanog.2012.88, 2012.

Marsland, S. J., Haak, H., Jungclaus, J. H., Latif, M., and Röske, F.: The Max Planck Institute global ocean/sea ice model with orthogonal curvilinear coordinates, Ocean Modell., 5, 91-127, 2003.

Martin, T., Park, W., and Latif, M.: Multi-centennial variability controlled by Southern Ocean convection in the Kiel Climate Model, Clim. Dynam., 40, 2005-2022, doi:10.1007/s00382-012-1586-7, 2013.

Massonnet, F., Mathiot, P., Fichefet, T., Goosse, H., Beatty, C. K., Vancoppenolle, M., and Lavergne, T.: Model reconstruction of the Antarctic sea ice thickness and volume changes over 1980-2008 using data assimilation, Ocean. Modell., 64, 67-75, doi:10.1016/j.ocemod.2013.01.003, 2013.

Meier, W. N., Gallaher, D., and Campbell, G. G.: New estimates of Arctic and Antarctic sea ice extent during September 1964 from recovered Nimbus I satellite imagery, The Cryosphere, 7, 699705, doi:10.5194/tc-7-699-2013, 2013.

Miller, G. H., Geirsdóttir, Á., Zhong, Y., Larsen, D. J., OttoBliesner, B. L., Holland, M. M., Bailey, D. A., Refsnider, K. A., Lehman, S. J., Southon, J. R., Anderson, C., Björnsson, H., and Thordarson, T.: Abrupt onset of the Little Ice Age triggered by volcanism and sustained by sea-ice/ocean feedbacks, Geophys. Res. Lett., 39, L02708, doi:10.1029/2011GL050168, 2012.

Niemeier, U., Timmreck, C., Graf, H.-F., Kinne, S., Rast, S., and Self, S.: Initial fate of fine ash and sulfur from large volcanic eruptions, Atmos. Chem. Phys., 9, 9043-9057, doi:10.5194/acp9-9043-2009, 2009.

Notz, D. and Marotzke, J.: Observations reveal external driver for Arctic sea-ice retreat, Geophys. Res. Lett., 39, L08502, doi:10.1029/2012GL051094, 2012.

Omrani, N.-E., Keenlyside, N., Bader, J., and Manzini, E.: Stratosphere key for wintertime atmospheric response to warm Atlantic decadal conditions, Clim. Dynam., 42, 649-663, doi:10.1007/s00382-013-1860-3, 2014.

Park, W. and Latif, M.: Multidecadal and multicentennial variability of the meridional overturning circulation, Geophys. Res. Lett., 35, L22703, doi:10.1029/2008GL035779, 2008.

Parkinson, C. L.: Southern Ocean sea ice and its wider linkages: insights revealed from models and observations, Antarctic Sci., 16, 387-400, doi:10.1017/S0954102004002214, 2004.

Polvani, L. M. and Smith, K. L.: Can natural variability explain observed Antarctic sea ice trends? New modeling evidence from CMIP5, Geophys. Res. Lett., 40, 3195-3199, doi:10.1002/grl.50578, 2013.

Raddatz, T. J., Reick, C. H., Knorr, W., Kattge, J. Roeckner, E. Schnur, R. Schnitzler, K.-G., Wetzel, P., and Jungclaus, J.: Will the tropical land biosphere dominate the climate-carbon cycle feedback during the twenty-first century?, Clim. Dynam., 29, 565-574, 2007. 
Robock, A., Adams, T., Moore, M., Oman, L., and Stenchikov, G.: Southern Hemisphere atmospheric circulation effects of the 1991 Mount Pinatubo eruption, Geophys. Res. Lett., 34, L23710, doi:10.1029/2007GL031403, 2007.

Roeckner, E., Brokopf, R., Esch, M., Giorgetta, M., Hagemann, S., Kornblueh, L., Manzini, E., Schlese, U., and Schulzweida, U.: Sensitivity of simulated climate to horizontal and vertical resolution in the ECHAM5 atmosphere model, J. Climate, 19, 37713791, doi:10.1175/JCLI3824.1, 2006.

Russell, J. L., Stouffer, R. J., and Dixon, K. W.: Intercomparison of the Southern Ocean Circulations in IPCC Coupled Model Control Simulations, J. Climate, 19, 4560-4575, 2006.

Sallée, J.-B., Shuckburgh, E., Bruneau, N., Meijers, A. J. S., Bracegirdle, T. J., and Wang, Z.: Assessment of Southern Ocean mixed layer depths in CMIP5 models: Historical bias and forcing response, J. Geophys. Res.-Oceans, 118, 1845-1862, doi:10.1002/jgrc.20157, 2013.

Schaefer, J. M., Denton, G. H., Kaplan, M., Putnam, A., Finkel, R. C., Barrell, D. J. A., Andersen, B. G., Schwartz, R., Mackintosh, A., Chinn, T., and Schlüchter, C.: High-frequency Holocene glacier fluctuations in New Zealand differ from the northern signature, Science, 324, 622-625, 2009.

Schleussner, C. F. and Feulner, G.: A volcanically triggered regime shift in the subpolar North Atlantic Ocean as a possible origin of the Little Ice Age, Clim. Past, 9, 1321-1330, doi:10.5194/cp-91321-2013, 2013.

Schubert, J. J., Stevens, B., and Crueger, T.: Madden-Julian oscillation as simulated by the MPI Earth System Model: Over the last and into the next millennium, J. Adv. Model. Earth Sys., 5, 71-84, doi:10.1029/2012MS000180, 2013.

Segschneider, J., Beitsch, A., Timmreck, C., Brovkin, V., Ilyina, T., Jungclaus, J., Lorenz, S. J., Six, K. D., and Zanchettin, D.: Impact of an extremely large magnitude volcanic eruption on the global climate and carbon cycle estimated from ensemble Earth System Model simulations, Biogeosciences, 10, 669-687, doi:10.5194/bg-10-669-2013, 2013.

Shakun, J. D., Clark, P. U., He, F., Marcott, S. A., Mix, A. C., Liu, Z., Otto-Bliesner, B., Schmittner, A., and Bard, E.: Global warming preceded by increasing carbon dioxide concentrations during the last deglaciation, Nature, 484, 49-54, doi:10.1038/nature10915, 2012.

Sigmond, M. and Fyfe, J. C.: The Antarctic Sea Ice Response to the Ozone Hole in Climate Models, J. Climate, 27, 1336-1342, doi:10.1175/JCLI-D-13-00590.1, 2014.

Simpkins, G. R., Ciasto, L. M., Thompson, D. W. J., and England, M. H.: Seasonal Relationships between Large-Scale Climate Variability and Antarctic Sea Ice Concentration, J. Climate, 25, 5451-5469, doi:10.1175/JCLI-D-11-00367.1, 2012.

Simpkins, G. R., Ciasto, L. M., and England, M. H.: Observed variations in multidecadal Antarctic sea ice trends during 1979-2012, Geophys. Res. Lett., 40, 1-6, doi:10.1002/grl.50715, 2013.

Simpson, I., Hitchcock, P., Shepherd, T., and Scinocca, J.: Southern Annular Mode Dynamics in Observations and Models. Part 1: the Influence of Climatological Zonal Wind Biases in a Comprehensive GCM, J. Climate, 26, 3953-3967, doi:10.1175/JCLI-D-1200348.1, 2012.
Stammerjohn, S., Massom, R., Rind, D., and Martinson, D.: Regions of rapid sea ice change: An inter-hemispheric seasonal comparison, Geophys. Res. Lett., 39, L06501, doi:10.1029/2012GL050874, 2012.

Stenchikov, G., Hamilton, K., Stouffer, R. J., Robock, A., Ramaswamy, V., Santer, B., and Graf, H.-F.: Arctic Oscillation response to volcanic eruptions in the IPCC AR4 climate models, J. Geophys. Res., 111, D07107, doi:10.1029/2005JD006286, 2006.

Stenchikov, G., Delworth, T. L., Ramaswamy, V., Stouffer, R. J., Wittenberg, A., and Zeng, F.: Volcanic signals in oceans, J. Geophys. Res., 114, D16104, doi:10.1029/2008JD011673, 2009.

Stier, P., Feichter, J., Kinne, S., Kloster, S., Vignati, E., Wilson, J., Ganzeveld, L., Tegen, I., Werner, M., Balkanski, Y., Schulz, M., Boucher, O., Minikin, A., and Petzold, A.: The aerosol-climate model ECHAM5-HAM, Atmos. Chem. Phys., 5, 1125-1156, doi:10.5194/acp-5-1125-2005, 2005.

Stössel, A., Zhang, Z., and Vihma, T.: The effect of alternative real-time wind forcing on Southern Ocean sea-ice simulations, J. Geophys. Res., 116, C11021, doi:10.1029/2011JC007328, 2011.

Stouffer, R. J., Broccoli, A. J., Delworth, T. L., Dixon, K. W., Gudgel, R., Held, I., Hemler, R., Knutson, T., Lee, H.-C., Schwarzkopf, M. D., Soden, B., Spelman, M. J., Winton, M., and Zeng, F.: GFDL's CM2 Global Coupled Climate Models. Part IV: Idealized Climate Response, J. Climate, 19, 723-740, doi:10.1175/JCLI3632.1, 2006.

Stroeve, J. C., Kattsov, V., Barrett, A. P., Serreze, M. C., Pavlova, T., Holland, M. M., and Meier, W. N.: Trends in Arctic sea ice extent from CMIP5, CMIP3 and observations, Geophys. Res. Lett., 39, L16502, doi:10.1029/2012GL052676, 2012.

Swart, N. C. and Fyfe, J. C.: Observed and simulated changes in southern hemisphere surface westerlies, Geophys. Res. Lett., 39, L16711, doi:10.1029/2012GL052810, 2012.

Thompson, D. W. J., Wallace, J. M., Jones, P. D., and Kennedy, J. J.: Identifying Signatures of Natural Climate Variability in Time Series of Global-Mean Surface Temperature: Methodology and Insights, J. Climate, 22, 6120-6141, 2009.

Tietsche, S., Notz, D., Jungclaus, J. H., and Marotzke, J.: Recovery mechanisms of Arctic summer sea ice, Geophys. Res. Lett., 38, L02707, doi:10.1029/2010GL045698, 2011.

Timmreck, C.: Modeling the climatic effects of large volcanic eruptions, WIREs Clim. Change, 3, 545-564, doi:10.1002/wcc.192, 2012.

Timmreck, C., Lorenz, S. J., Crowley, T. J., Kinne S., Raddatz, T. J., Thomas, M. A., and Jungclaus, J. H.: Limited temperature response to the very large AD 1258 volcanic eruption, Geophys. Res. Lett., 36, L21708, doi:10.1029/2009GL040083, 2009.

Timmreck, C., Graf, H.-F., Lorenz, S. J., Niemeier, U., Zanchettin, D., Matei, D., Jungclaus, J. H., and Crowley, T. J.: Aerosol size confines climate response to volcanic super-eruptions, Geophys. Res. Lett., 37, L24705, doi:10.1029/2010GL045464, 2010.

Timmreck, C., Graf, H.-F., Zanchettin, D., Hagemann, S., Kleinen, T., and Krüger, K.: Climate response to the Toba eruption: regional changes, Quaternary Int., 258, 30-44, 2012.

Turner, J., Comiso, J. C., Marshall, G. J., Lachlan-Cope, T. A., Bracegirdle, T., Maksym, T., Meredith, M. P., Wang, Z., and Orr, A.: Non-annular atmospheric circulation change induced by stratospheric ozone depletion and its role in the recent increase of Antarctic sea ice extent, Geophys. Res. Lett., 36, L08502, doi:10.1029/2009GL037524, 2009. 
Turner, J., Bracegirdle, T., Phillips, T., Marshall, G. J., and Hosking, J. S.: An Initial Assessment of Antarctic Sea Ice Extent in the CMIP5 Models, J. Climate, 26, 1473-1484, doi:10.1175/JCLID-12-00068.1, 2013.

Wang, M. and Overland, J. E. E.: A sea ice free summer Arctic within 30 years-an update from CMIP5 models, Geophys. Res. Lett., 39, L18501, doi:10.1029/2012GL052868, 2012.

Weber, M. E., Clark, P. U., Ricken, W., Mitrovica, J. X., Hostetler, S. W., and Kuhn, G.: Interhemispheric Ice-Sheet Synchronicity During the Last Glacial Maximum, Science, 334, 1265-1269, doi:10.1126/science.1209299, 2011.

Weijer, W., Sloyan, B. M., Maltrud, M. E., Jeffery, N., Hecht, M. W., Hartin, C. A., van Sebille, E., Wainer, I., and Landrum, L.: The Southern Ocean and its climate in CCSM4, J. Climate, 25, 2652-2675, doi:10.1175/JCLI-D-11-00302.1, 2012.

Wetzel, P., Winguth, A., and Maier-Reimer, E.: Sea-to-air $\mathrm{CO}_{2}$ fluxes from 1948 to 2003, Global Biogeochem. Cy., 19, GB2005, doi:10.1029/2004GB002339, 2005.

Zanchettin, D., Timmreck, C., Graf, H.-F., Rubino, A., Lorenz, S., Lohmann, K., Krueger, K., and Jungclaus, J. H.: Bi-decadal variability excited in the coupled ocean-atmosphere system by strong tropical volcanic eruptions, Clim. Dynam., 39, 419-444, doi:10.1007/s00382-011-1167-1, 2012.
Zanchettin, D., Bothe, O., Graf, H. F., Lorenz, S. J., Luterbacher, J., Timmreck, C., and Jungclaus, J. H.: Background conditions influence the decadal climate response to strong volcanic eruptions, J. Geophys. Res.-Atmos., 118, 4090-4106, doi:10.1002/jgrd.50229, 2013a.

Zanchettin, D., Rubino, A., Matei, D., Bothe, O., and Jungclaus, J. H.: Multidecadal-to-centennial SST variability in the MPI-ESM simulation ensemble for the last millennium, Clim. Dynam., 40, 1301-1318, doi:10.1007/s00382-012-1361-9, 2013b.

Zhang, J.: Increasing Antarctic Sea Ice under Warming Atmospheric and Oceanic Conditions, J. Climate, 20, 2515-2529, doi:10.1175/JCLI4136.1, 2007.

Zhang, J.: Modeling the impact of wind intensification on Antarctic sea ice volume, J. Climate, 27, 202-214, doi:10.1175/JCLI-D12-00139.1, 2013.

Zhong, Y., Miller, G. H., Otto-Bliesner, B. L., Holland, M. M., Bailey, D. A., Schneider, D. P., and Geirsdottir, A.: Centennialscale climate change from decadally-paced explosive volcanism: a coupled sea ice-ocean mechanism, Clim. Dynam., 37, 23732387, doi:10.1007/s00382-010-0967-z, 2011. 